Research Article

\title{
The Impact of Advance Selling Strategies on a Three-Echelon Supply Chain in the Presence of Social Influence
}

\author{
Qianyu Niu (D) and Feng Yang $(\mathbb{D}$ \\ School of Management, University of Science and Technology of China, 96 Jinzhai Road, Hefei, Anhui 230026, China \\ Correspondence should be addressed to Qianyu Niu; nqianyu@mail.ustc.edu.cn
}

Received 15 December 2019; Revised 7 March 2020; Accepted 23 March 2020; Published 29 April 2020

Academic Editor: Sri Sridharan

Copyright ( ) 2020 Qianyu Niu and Feng Yang. This is an open access article distributed under the Creative Commons Attribution License, which permits unrestricted use, distribution, and reproduction in any medium, provided the original work is properly cited.

As the quality of new products is ex-ante uncertain, social influence plays an important role in the diffusion of a new product. An important question is how to expand public knowledge about consumer experience with a new product by using promotion strategies. This paper discusses the impact of advance selling strategies on a three-echelon supply chain when upstream enterprises launch a new product facing strategic consumers under social influence. This problem is modeled as a Stackelberg game, and a two-advance-selling-discount model is presented. Furthermore, we consider the impact of advance purchase behavior on the financing strategy when the retailer places an advance order. Several results are obtained: (i) the consumers' utility in the second period is increasing in the number of predecessors. (ii) Upstream enterprises will provide deeper advance selling discounts when consumers become more patient or predecessors have a greater influence on imitators. Moreover, the total demand will increase when the consumer's discount factor decreases or the impact intensity of predecessors increases. However, high innovation levels will drive enterprises to set high advance selling discounts. We also obtain the condition under which the total demand increases quickly as the innovation level changes. (iii) The two-advanceselling-discount model yields Pareto-improved results compared with the case where there is no advance purchase, though it cannot coordinate the supply chain. Finally, we extend the model to analyze the two-advance-selling-discount model with a minimum order quantity constraining the precommitted order quantity, and we show this can allow the enterprises to increase their profits. We also determine a condition under which the upstream enterprises should put a constraint on the minimum order quantity.

\section{Introduction}

When a product of uncertain quality is first introduced to the market (e.g., hi-tech products), except for those who are sensitive to the innovation level, other consumers who lack sufficient knowledge about the product are usually influenced by the actions of predecessors. Thus, these consumers may delay their purchase decisions strategically in anticipation of product reviews (e.g., from online retailers such as JD), which can be shaped by word of mouth from peers offline or by the reviews online. Especially in the era of online shopping, most consumers are exposed to a large number of product reviews, which in turn influence their purchase decisions. Thus, for a new product, socially shared purchasing has become a mainstream activity of consumers and one of the top drivers for online sales. Social influence is a process in which consumers update their beliefs by observing others' actions and experiences. However, social influence may exacerbate strategic consumer behavior. Thus, some firms offer promotional incentives to recruit some consumers to be influencers, such as advance selling strategy and price guarantee [1]. Research has revealed that a very small number of such influencers are sufficient to diminish sales unpredictability [2]. Shao and $\mathrm{Hu}[3]$ point out that firms incentivize influencers to spread product information and from these influencers collect data on demand and feedback for product improvement before further production. Importantly, advance selling strategies have positive effects on profits in the product diffusion when the social network exists. Thus, it is important to analyze how the 
emerging practice of using advance selling strategies, which are regarded as one of the intrinsic driving factors of social contagion, mitigates the negative impact of social influence and then affects the process of new product diffusion.

Furthermore, some small and medium-sized suppliers often have no significant liquid funds to invest in new product production. Thus, upstream enterprises presell a new product and solicit financial contributions from consumers to cover production costs. In the presence of advance selling strategies, retailers are willing to commit to delivering an advance purchase order to suppliers. Because these small and medium-sized suppliers often face challenges in obtaining financing when launching new products, some researchers have put forward buyer-intermediated financing, by which large buyer intermediaries help suppliers obtain loans from financing institutions [4]. However, in the context of advance selling strategies, buyer intermediaries will receive advance payments from consumers before they place orders. Thus, we consider the impact of advance selling strategies on the financing strategy when the advance purchase behavior occurs within the supply chain. Specifically, buyer intermediaries will change from facilitating buyer-intermediated financing to facilitating supply chain internal financing, thereby solving the supplier's problem of financial constraints through advance selling funds.

Much research focuses on product diffusion under social contagion, social learning, or social influence. However, most of this literature just focuses on how the diffusion mechanism works among consumers, while, in contrast, we consider the process of new product diffusion in a threeechelon supply chain. Moreover, though many papers have introduced buyer-intermediated financing, it is instructive to analyze how buyer intermediaries change their effect from buyer-intermediated financing to supply chain internal financing. In this study, we consider a three-echelon supply chain with an upstream supplier that invests in innovation to launch new products and a downstream retailer or platform which sells to consumers. The following questions are addressed in the present study:

(i) How do consumers make purchase decisions based on their gross utility?

(ii) How do the parameters affect the total number of consumers who choose to purchase?

(iii) How do the supplier and retailer determine the optimal advance selling discounts when facing strategic consumers who interact socially through product reviews or their peers' comments, altering plans because of social influence?

(iv) When should the upstream supplier set a constraint on the minimum precommitted quantity?

To answer these questions, we consider a three-echelon supply chain with two advance selling discounts: one discount is between the supplier and the retailer, and the other is between the retailer and the consumers. This model with two discounts is called the two-advance-selling-discount (TASD) model. We divide the selling season into two transaction periods. In the first period, the supplier offers an advance selling discount to the retailer, and the retailer offers an advance selling discount to consumers. Thus, upstream firms can receive precommitted orders and the supplier can obtain production costs. In the second period, regular orders are traded at regular prices. Consumers are divided into influencers and imitators in this study. Influencers will purchase the new product in the first period, while imitators' purchase decisions in the second period are shaped by their preferences regarding the innovation level and the social influence which comes from influencers. The total consumer demands in the first and second periods are analyzed first. Then, we derive the basis for the optimal discounts. Next, we compare the TASD model with the base case where neither the supplier nor the retailer offers an advance selling discount. Finally, we extend our model by considering a constraint on the minimum order quantity under social influence. Our analysis yields the insights summarized below.

For consumers, we show that their utility in the second period is increasing in the number of consumers who purchase in the first period. Specifically, the two advance selling discounts are decreasing in both the consumer's discount factor and the impact intensity of predecessors, whereas the discounts are increasing in the innovation level. Thus, the supplier and the retailer will provide deeper advance selling discounts when consumers become more patient or predecessors have a greater influence on imitators. However, high innovation levels will drive enterprises to set high advance selling discounts. Besides this, the total demand is decreasing in the consumer's discount factor and increasing in the impact intensity. We also obtain the conditions under which the demands change with the innovation level. For the supplier and the retailer, the TASD model is Pareto-improved compared with the base case where there is no advance selling discount. Although the TASD model cannot coordinate the supply chain, it can improve supply chain efficiency by incorporating a minimum precommitted quantity. We also determine conditions under which the upstream supplier should set a constraint on the precommitted order quantity.

Our study is organized as follows. Section 2 reviews the related literature. Section 3 presents the setup of the TASD model and describes the individual consumer's decisionmaking. Section 4 analyzes optimal decisions in the TASD model and then compares the TASD model with the base case and centralized case. Section 5 characterizes the model with a constraint on the precommitted quantity. Section 6 provides numerical examples to verify the results. Section 7 presents conclusions and future research suggestions. Proofs are provided in the Appendix.

\section{Literature Review}

This paper is related to three streams of literature: strategic consumer behaviors, sociology and diffusion research, and advance selling strategies. The phenomenon of strategic consumer behavior has been widely discussed. To maximize the expected surplus, strategic consumers anticipate future sales and choose arrival times to purchase according to 
individual thresholds which depend on their base value and the behavior of other consumers [5-7]. The decentralized supply chain can use contracts (e.g., wholesale price, buyback, and revenue-sharing contracts) to attain a desired outcome $[8,9]$. This stream of research captures the consumers' response to the sellers' pricing, production, and inventory policies. However, these publications rarely incorporate social influence and quality uncertainty into a new product diffusion model to characterize strategic consumers' purchase decisions.

Second, there has been a growing body of literature that describes how a new product of unknown quality diffuses in the market via contagion, social influence, and social learning [10]. Some researchers model the aggregate-level diffusion of innovations in markets with influencers and imitators, which are consistent with "viral" or "network" marketing strategies, and the internal interactions among influencers and imitators have been widely discussed (see, e.g., [11-14]). Hu et al. [2] point out that some consumers will be responsive to predecessors' purchase decisions. Thus, social influence would amplify demand uncertainty. They build a model to study the influence of social influence on the policies of a newsvendor-type firm and propose that the firm can recruit consumers as influencers by offering promotional incentives. Papanastasiou and Savva [15] study the impact of social learning on the interaction between the firm and the consumer. Their analysis yields that an increasing price plan is typically implemented when the firm uses a preannounced pricing strategy in the presence of social learning. This result is consistent with the advance purchase discount in the two-period model.

Because the social influence and peer influence can result in network externalities, under which the value of a product increases with the number of predecessors $[16,17]$, many researchers incorporate the network effect into the new innovative product's diffusion model. Sun et al. [18] use the expected network size and the strength of the network effect to characterize consumers' utility. Chau and Desiraju [19] describe network benefits through the total number of consumers who purchase early and the influence of the installed base on consumers' willingness to pay. Especially due to the development of computing technology, "personal interaction" has been incorporated into the purchasing process. It is common that consumers interact with each other through internet-based channels, and it is convenient for marketers to manage consumer relationships online (e.g., e-commerce and social media) $[20,21]$.

Apart from the aforementioned streams of literature, our study contributes to the literature about advance selling and financial constraints. Advance selling is a retail practice of accepting downstream enterprises' purchase orders before a product is released. Such orders are helpful to facilitate demand learning and predict the regular selling season's demand more accurately via the number of preorders from the advance selling strategies [22]. For a riskaverse firm, Ma et al. [23] examine when and why to implement the advance booking discount program. They point out that if the product has a low wholesale price while the coefficient of variation in demand is high, it is optimal for the firm to offer a discount before the selling season. Wei and Zhang [7] present a sequential-move game where a seller sells perishables in two periods. Importantly, the seller determines their advance selling policy and consumers make purchase decisions in the second period while considering the decisions of those who have purchased in the first period.

As the Internet becomes a common method to fund a project, crowdfunding is a modern technique to fundraise from a large number of people. On the one hand, online crowdfunding platforms can reduce entrepreneurs' costs of introducing their projects by offering more potential funders before production. On the other hand, crowdfunding can be regarded as a market test that adapts production to demand. Only when the aggregate funding reaches the threshold does the production occur [24]. Crowdfunding is similar to advance selling because they both encourage consumers to purchase before the product is released. Xu and Zhang [25] consider a situation where firms develop new products by preselling to raise money without incurring debt or sacrificing equity or shares. They point out two features of crowdfunding: one is that consumers learn the true quality of a new product through product reviews. The other is that crowdfunded products often exhibit positive network externalities. Thus, in the presence of advance selling and crowdfunding, there will be changes in financing methods. Because traditional financing methods can be costly to small suppliers needing to fund their operations, large buyers who act as intermediaries or underwriters sometimes launch a finance intermediation service to ease the suppliers' financing cost and expand their feasible production set $[4,26]$. Moreover, the buyer intermediation can bring the buyers a benefit from a lower purchasing price, which results from a lower buyer-finance interest rate compared with bank financing [27].

Our study is closely related to the abovementioned research, but our study differs from it in two aspects. First, though many works explore strategic consumer behavior, they rarely consider social influence and quality uncertainty. Our study focuses on the role of positive social influence on the diffusion of a new product in a three-echelon supply chain. Specifically, we endogenize consumer demand uncertainty by relating this uncertainty to the consumers' sensitivity to the number of predecessors. Second, social learning plays an important role in crowdfunding, but network externalities and financial constraints are rarely considered in the advance selling policy. Thus, we combine the social influence and fundraising with the new product's diffusion and advance selling policy based on the prevailing phenomena seen in real life. In other words, our study considers the impact of an advance selling policy on the financing strategy when advance purchase behavior is introduced into a three-echelon supply chain, by which buyer intermediaries will change from facilitating buyer-intermediated financing to facilitating supply chain internal financing. 


\section{Model Development}

3.1. The Setup. We consider a three-echelon supply chain consisting of a supplier who invests in innovations and develops a new product, a retailer, and consumers. There are two periods in our model. Preorders are delivered in the advance selling season (the first period), during which specifications of the new product are unknown to consumers. Later, the supplier releases the new product to the spot market in the regular selling season (the second period). The consumers' purchase decisions are shaped by both their preference for innovation and social influence. We define consumers who deliver advance orders in the first period as influencers and those who purchase in the second period as imitators. The upstream enterprises can know the distribution of consumerintrinsic preferences through comprehensive market research before launching a new product. However, there may still be some uncertainties of the demand realization because of the sale process in the presence of social influence.

For tractability, we make the following assumptions. First, we consider heterogeneous consumers who have varying beliefs about the new product. Second, we assume that the supplier launches a new product with an exogenous innovation level. Third, the regular selling prices are set by the market because in most supply chains, the firms establish a relationship for the product by agreeing on a price contract long before the actual production is initiated or any forecast update is realized. This price would be set by the market. However, the upstream enterprises can determine advance purchase prices at their own discretion. Thus, the supplier and the retailer can determine advance selling discounts to maximize their own profits based on the price set by the market. Fourth, without loss of generality, we assume the products remaining at the end of the second period have zero salvage value, and in the event of stockout, unmet demand has no additional stockout penalty. Fifth, we assume $\alpha>Q>p$. That is, the utility coming from the impact of influencers on consumers' willingness to pay in the second period is larger than the utility coming from the new innovation level. As online shopping carnivals (e.g., Double 11) and impulse buying become more common, the consumer's social community consisting of the connections with the e-commerce platform, the media, net friends, and close friends becomes a significant factor in promoting the impulse buying [28]. Thus, as promotions increase, consumer sensitivity to the experience of predecessors can be larger than their personal preference for the product. Togawa et al. [29] point out that after impulse buying, consumers can obtain a strong feeling of pleasure. Thus, for the new fashion, high-tech, or perishable products, consumers prefer to purchase as soon as possible to obtain satisfaction and pride, while also avoiding the risk of stockout. Therefore, consumer sensitivity to the innovation level is expected to be larger than that to the price. In other words, the utility coming from the new innovation level is expected to be larger than the utility coming from the price. Finally, for simplicity, we do not consider the supplier's and the retailer's discount factors in our analysis and we do not consider the supplier's unit production cost.
For easy reference, Table 1 summarizes the notation used throughout the paper.

3.2. Individual's Decision-Making. We begin by analyzing the consumers' choices. Consumer purchase decisions are shaped by individual preference and social influence. Their gross utility of purchasing a new product is given by the sum of a utility measuring their sensitivity to the new product's innovation level and a social utility. The gross utility minus the price is the net utility. We assume that consumers are distributed uniformly over the preference line. Each consumer is characterized by a parameter $\beta \in[-M, 1]$, where $M>0$, representing their preference for the innovation level. As the network effects exist, we can avoid considering the situation where all consumers enter the market when $M$ is sufficiently large. That is, $\beta$ is assumed to have no finite lower limit so as to avoid considering corner solutions $[18,19,30]$. The larger $\beta$ is, the more sensitive consumers are to the innovation level.

The consumers who purchase the new product in the first period report their ex-post experience to the rest of the market through reviews (e.g., via an online review platform), the effect of which we call social influence. The social utility for a new product is specified as a proportional function of the number of influencers, denoted by $\alpha x$. For the improvable durable good (such as packaged software), Sankaranarayanan [31] has assumed that the network coefficient is greater than the incremental quality differential between the new version and the previous version, by which it is tractable to analyze and deal with a subset of the parameter space. Previous work has made similar assumptions. Following Ellison and Fudenberg [32], when a software supplier wants to provide an upgraded version, it is possible that there may be a negative correlation between the installed base and the network externality, although it is less likely. However, someone who has a higher preference for the product will also assign more importance to the network effect. Thus, the network effect is positive. Xu and Zhang [25] also point out that crowdfunding products often exhibit positive network externalities. In our study, we do not consider the function of competitive products when launching a new product version. Thus, consumers will obtain more useful experience from those who have adopted the new product than the case where there is no social study before they purchase. For example, if a new version of Microsoft Word is adopted by a large number of users, then the users of the old version will encounter many documents created by the new version, which are unreadable with the old version. In this case, accepting documents from colleagues is valuable enough that the new version will be acquired, even if the user has no use for the distinct functions only in the new version. Thus, the network effect is positive.

At the beginning of the first period, both the discount price $\delta_{2} p$ and the regular price $p$ are announced by the retailer. The consumers' net utility of purchasing the new product in the first period is $U_{1}=\beta Q-\delta_{2} p$. However, if they delay their purchase decision until the second period, then the net utility is $U_{2}^{\prime}=\delta_{c}(\beta Q+\alpha x-p)$, where 
TABLE 1: Notation of parameters and decision variables.

\begin{tabular}{|c|c|}
\hline \multicolumn{2}{|c|}{ Exogenous parameters } \\
\hline$r$ & Regular contract price that the supplier quotes to the retailer \\
\hline$p$ & Regular selling price of the product \\
\hline$b$ & Unit price at which the supplier salvages surplus products \\
\hline$\xi$ & Development cost coefficient \\
\hline Q & Innovation level \\
\hline$\delta_{c}$ & Consumer's discount factor that applies to the second-period purchase $\left(0 \leq \delta_{c} \leq 1\right)$ \\
\hline$\alpha$ & Impact intensity of predecessors on the willingness to pay of consumers who purchase in the second period \\
\hline$\gamma$ & A financial parameter denoting the fraction that the precommitted order extends to its total value \\
\hline \multicolumn{2}{|c|}{ Uncertainty-related notation } \\
\hline$x$ & Number of predecessors who purchase the product in the first period \\
\hline$\beta$ & Consumer preferer \\
\hline \multicolumn{2}{|c|}{ Decision variables } \\
\hline$\delta_{1}$ & Advance selling discount set by the supplier \\
\hline$\delta_{2}$ & Advance selling discount set by the retailer \\
\hline$\delta_{m 1, b 1}$ & Advance selling discount set by the supplier when there is a constraint on the precommitted order quantity \\
\hline$\delta_{m 2, b 2}$ & Advance selling discount set by the retailer when there is a constraint on the precommitted order quantity \\
\hline$\beta_{0}$ & Threshold of consumer preference when there is no advance purchase behavior in the supply chain \\
\hline$\beta_{i}$ & Threshold of consumer preference in the period $i(i=1,2)$ when there are two advance selling discounts \\
\hline$D_{0}$ & Consumer demand when there is no advance purchase behavior in the supply chain \\
\hline$D_{i}$ & Consumer demand in the period $i(i=1,2)$ when there are two advance selling discounts \\
\hline$D$ & Consumer total demand in the first and second periods \\
\hline$D_{m, b}$ & Minimum precommitted order quantity set by the supplier \\
\hline$D_{m i, b i}$ & Consumer demand in the period $i(i=1,2)$ when there is a constraint on the precommitted order quantity \\
\hline$U_{0}$ & Consumer net utility when there is no advance purchase behavior in the supply chain \\
\hline$U_{i}$ & Consumer net utility in the period $i(i=1,2)$ when there are two advance selling discounts \\
\hline$U_{2}^{\prime}$ & The consumers' net utility if they delay the purchase decision until the second period \\
\hline
\end{tabular}

$\delta_{c} \in[0,1]$ is a discount factor that applies to the secondperiod purchase. Parameter $\delta_{c}$ describes the opportunity cost of delaying adoption, and it may also be regarded as a measure of consumer patience $[6,15]$. Thus, it can reflect how "strategic" consumers are in the supply chain. At the beginning of the second period, imitators observe influencers' reviews and update their common beliefs about the new product's innovation level. Therefore, the consumers' net utility of purchasing the new product in the second period is $U_{2}=\beta Q+\alpha x-p$.

We assume that influencers purchase the new product in the first period if and only if the following two conditions hold simultaneously: (i) the utility from purchasing in the first period is not lower than the utility of delaying their purchase decisions and (ii) the utility from purchasing in the first period is nonnegative. The imitators purchase the new product provided that the utility from purchasing in the second period is nonnegative.

3.3. The Base Case. Consider a base case in which neither the supplier nor the retailer offers an advance selling discount. Thus, there is no advance purchase behavior in the supply chain and consumers will just purchase the new product during the selling season, provided that the utility from purchasing in the second period is nonnegative. Let $U_{0}$ denote consumers' net utility, which is given by

$$
U_{0}=\beta Q-p .
$$

Thus, the profits of the retailer and the supplier for rush orders, which we denote by $\pi_{0}^{R}$ and $\pi_{0}^{S}$, respectively, are

$$
\begin{aligned}
& \pi_{0}^{R}=p D_{0}-r D_{0}, \\
& \pi_{0}^{S}=r D_{0}-\xi Q^{2},
\end{aligned}
$$

where $\xi Q^{2}$ represents the development cost that the supplier invests in an innovation level, which reflects diseconomies of scale in production. Raz et al. [33] point out that the firm can invest in an effort to improve the innovative product's performance at a cost described by a quadratic function. Other researchers also propose that the innovation investment cost is a quadratic function of quality when the firm develops products or delivers greater quality levels [34, 35]. Also, the supply chain's total profit is $\pi_{0}=p D_{0}-\xi Q^{2}$.

3.4. Two-Advance-Selling-Discount Model. First, we analyze a centralized system where the parties operate under a central planner. Given consumer demands in the first and second periods, the profit of the central planner can be written as follows:

$$
\pi_{C}\left(\delta_{2}\right)=p D_{2}+\delta_{2} p D_{1}-\xi Q^{2},
$$

subject to

$$
\xi Q^{2} \leq \gamma \delta_{2} p D_{1}
$$

where $\gamma \in[0,1]$. Note that there exists a financial constraint for small and medium-sized suppliers when they launch new products. That is, the production cost cannot exceed the revenue from precommitted orders from retailers, which not only relaxes the financial constraint on the supplier but also 
extends the supplier's credit limit. Thus, the source of the production funding comes not only from the funds raised by the supplier himself but also from the downstream enterprises. For tractability, we do not consider the funds raised by the supplier. However, the precommitted order only extends to a fraction of its total value [26]. Let $\gamma \in[0,1]$ denote this fraction, which is a financial parameter. With a higher $\gamma$, the retailer will have less uncertainty about the supplier's ability to comply with the contract. In other words, the precommitted order enables the supplier to borrow $\gamma \delta_{2} p D_{1}$ of additional funds. We assume that the retailer is risk-free and bound to place the precommitted order, which is equal to the quantity of orders from consumers prior to the start of production. Then, the supplier begins the production according to the precommitted order in the first period.

Next, we consider the decentralized three-echelon supply chain where the supplier offers an advance selling discount $\delta_{1}$ and the retailer offers an advance selling discount $\delta_{2}$. The sequence of events under the TASD model is summarized in Figure 1. In the first period, the supplier determines the advance selling discount $\delta_{1}$ and then the retailer determines the advance selling discount $\delta_{2}$. Influencers will deliver the quantity of precommitted orders $D_{1}$ at a discount price $\delta_{2} p$. Then, the retailer orders $D_{1}$ from the supplier at a discount price $\delta_{1} r$, and the supplier decides to produce $D_{1}$ products. Upon arrival in the second period, each imitator can observe the purchase decisions made by influencers. Transactions will be made at the regular selling price $p$, and $D_{2}$ is realized. Then, the retailer orders $D_{2}$ at the regular wholesale price $r$ and the supplier produces $D_{2}$ during the second period.

We characterize the decision variables $\delta_{1}$ and $\delta_{2}$ by using backward induction. Given consumer demands in the first and second periods, the retailer needs to determine the advance selling discount $\delta_{2}$ in the first period by solving the following problem:

$$
\pi_{R}\left(\delta_{2}\right)=\left(\delta_{2} p-\delta_{1} r\right) D_{1}+(p-r) D_{2} .
$$

Similarly, by considering the supplier's financial constraint as in the centralized system, we obtain the supplier's profit as follows:

$$
\pi_{S}\left(\delta_{1}\right)=\delta_{1} r D_{1}+r D_{2}-\xi Q^{2},
$$

subject to

$$
\xi Q^{2} \leq \gamma \delta_{1} r D_{1} .
$$

Inequality (8) represents the financial constraint: the production cost cannot exceed the financing available from the retailer's commitment.

\section{Analysis}

The analysis proceeds as follows. Subsection 4.1 characterizes consumer demands in the first and second periods. Subsection 4.2 determines the optimal advance selling discounts $\delta_{1}$ and $\delta_{2}$. Subsection 4.3 compares the TASD model with the base case and the centralized case in terms of the profits.
4.1. Consumers' Purchasing Strategy. We discuss the base case first in which each consumer purchases the new product if and only if the utility from purchasing in the second period is nonnegative. Thus, we have $\beta \geq \beta_{0}$, where $\beta_{0}=p / Q$, and the demand $D_{0}$ is

$$
D_{0}=\frac{Q-p}{Q} .
$$

Next, we analyze a general model wherein there are two periods, and consumers interact with each other under social influence to learn about the new product's unknown quality. To reflect how the actions of influencers affect the utility of imitators, we assume each advance purchase in the first period generates a review because influencers gain experience with the new product. Later, the review enables imitators to make a better-informed purchase decision. To obtain the consumers' equilibrium purchase strategy, we first make use of the following lemma.

Lemma 1. An individual consumer's utility in the second period is increasing in the number of the consumers who purchase in the first period.

Proof. See the appendix.

When there is no social influence, the consumers' net utilities of purchasing a new product in the first and second periods are given by $U_{1}^{n}=\beta Q-\delta_{2} p$ and $U_{2}^{n}=\beta Q-p$, respectively. From Lemma 1, because a positive number of consumers purchase in the first period, we have $\delta_{c}(\beta Q+\alpha x-p)>\delta_{c}(\beta Q-p)$. That is, the utility in the second period with social influence is larger than the utility without social influence. Because the first-period purchase threshold $\beta$ satisfies $\beta Q-\delta_{2} p=\delta_{c}(\beta Q+\alpha(1-\beta)-p)$ and $\delta_{c}(\beta Q+\alpha(1-\beta)-p)>\delta_{c}(\beta Q-p)$, the equilibrium $\beta$ satisfies $\beta Q-\delta_{2} p>\delta_{c}(\beta Q-p)$. At the extreme case of $\delta_{c}=1$, the last inequality implies $p>\delta_{2} p$. That is, $\delta_{2}<1$. Thus, when the advance selling discount $\delta_{2}$ is lower than 1 , it is beneficial for the retailer to have more consumers purchase the new product in the first period, which increases the utility of purchasing the product in the second period.

According to the abovementioned conclusion, Lemma 2 describes the consumers' equilibrium purchase strategy under social influence when there are two periods in the three-echelon supply chain.

Lemma 2. For any given price plan $\left\{\delta_{2} p, p\right\}$, there exists a unique equilibrium in the purchase game which is played by influencers and imitators. Specifically,

(i) In the first period, consumers will purchase the new product if $\beta \geq \beta_{1}$, where

$$
\beta_{1}= \begin{cases}\frac{\delta_{2} p+\delta_{c}(\alpha-p)}{Q+\delta_{c}(\alpha-Q)}, & \text { if } \delta_{2} \leq \frac{Q-\delta_{c}(Q-p)}{p}, \\ 1, & \text { if } \delta_{2}>\frac{Q-\delta_{c}(Q-p)}{p}\end{cases}
$$




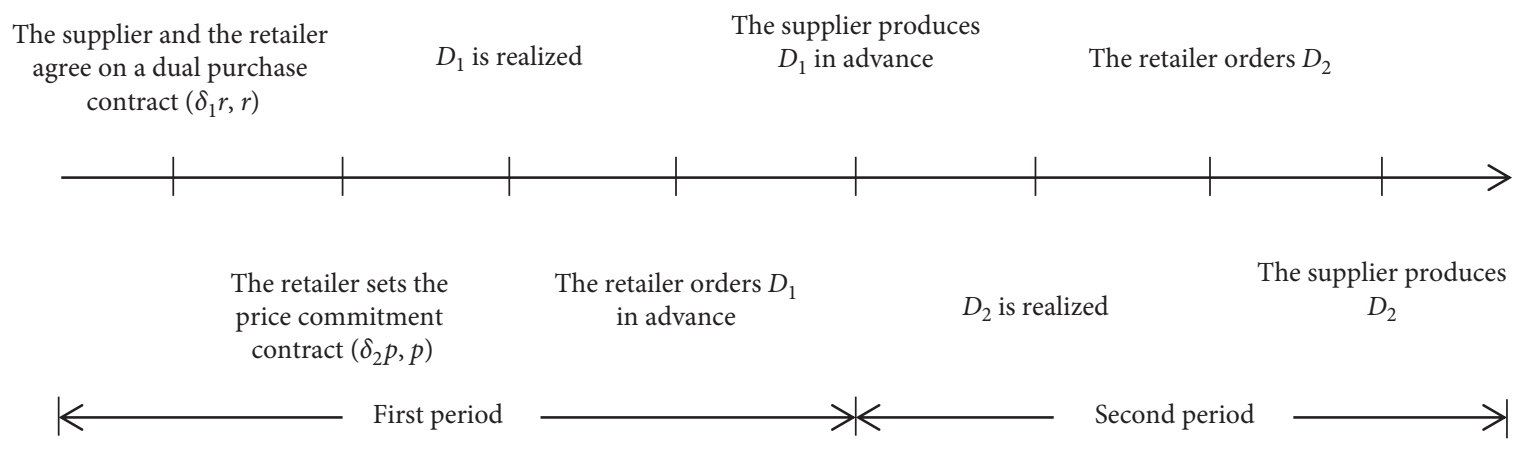

Figure 1: Sequence of events under the TASD model.

The threshold $\beta_{1}$ is increasing in $\delta_{c}$ and decreasing in p. Moreover, $\beta_{1}$ is increasing in $Q$ and decreasing in $\alpha$, provided that $p>\delta_{c} Q$.

(ii) In the second period, consumers purchase the new product if $\beta_{2} \leq \beta<\beta_{1}$, where

$$
\begin{aligned}
& \beta_{1}=\frac{\delta_{2} p+\delta_{c}(\alpha-p)}{Q+\delta_{c}(\alpha-Q)}, \\
& \beta_{2}=\frac{\left(1-\delta_{c}\right)(p-\alpha)}{Q+\delta_{c}(\alpha-Q)}+\frac{\delta_{2} p \alpha}{Q\left(Q+\delta_{c}(\alpha-Q)\right)} .
\end{aligned}
$$

The threshold $\beta_{2}$ is increasing in $\delta_{c}$ and decreasing in $\alpha$.

Proof. See the appendix.

Lemma 2 states that if the advance selling discount $\delta_{2}$ satisfies the condition $\delta_{2}>\left(Q-\delta_{c}(Q-p)\right) / p$, then all consumers will choose to defer their purchase decisions as a result of the price benefit in the second period, even though their decisions will be made without any information from early purchase reviews (since no purchases occur in the first period). On the contrary, if the advance selling discount $\delta_{2}$ satisfies the condition $\delta_{2} \leq\left(Q-\delta_{c}(Q-p)\right) / p$, then a positive number of consumers purchase the new product in the first period. Specifically, the influencers will purchase in the first period if $\beta \geq \beta_{1}$ and the imitators will purchase in the second period if $\beta_{2} \leq \beta<\beta_{1}$. If consumers realize that they will not suffer much loss by delaying the purchase decision, the threshold will increase as consumers becoming more patient. For the influencers, the higher the price is, the higher the quality. Thus, a large number of consumers will choose to purchase, and the threshold will decrease. In our study, we assume $p>\delta_{c} Q$, which means that if the consumers who are more sensitive to the innovation level choose to delay purchasing until the second period, their utility from the innovation level will be lower than that from the price. Otherwise, they will not be willing to purchase in the first period. The high impact intensity of predecessors requires a large installed base; thus, the threshold will decrease.

Consumer demands in the first and second periods, which we denote by $D_{1}$ and $D_{2}$, respectively, are given by

$$
\begin{aligned}
& D_{1}=\frac{Q-\delta_{2} p+\delta_{c}(p-Q)}{Q+\delta_{c}(\alpha-Q)}, \\
& D_{2}=\frac{\delta_{2} p(Q-\alpha)+Q(\alpha-p)}{Q\left(Q+\delta_{c}(\alpha-Q)\right)} .
\end{aligned}
$$

Thus, the consumers' total demand during these two periods is as follows:

$$
D=\frac{Q^{2}-p Q+\alpha Q+\delta_{c} Q(p-Q)-\delta_{2} p \alpha}{Q\left(Q+\delta_{c}(\alpha-Q)\right)} .
$$

The following proposition characterizes the properties of consumer demands in the first and second periods.

\section{Proposition 1}

(i) $D_{1}$ is decreasing in $\delta_{c}$ and $Q$, and increasing in $\alpha$ and $p$.

(ii) $D_{2}$ is decreasing in $\delta_{c}$, and increasing in $\alpha$. If $\alpha<3 Q$, then $\mathrm{D}_{2}$ is decreasing in $p$.

(iii) The total demand $D$ is decreasing in $\delta_{c}$, and increasing in $\alpha$. If $\alpha<2 Q$, then $D$ is decreasing in $p$. Let $Q_{i}(i=1,2,3,4)$ denote the solutions to the following equation:

$$
\begin{aligned}
& \left(\alpha Q^{4}-4 p Q^{4}\right)\left(1-\delta_{c}\right)^{3}+\alpha p\left(-3 Q^{3}\left(3 \delta_{c}+1\right)\left(1-\delta_{c}\right)^{2}\right) \\
& \quad+3 \alpha Q^{2}\left(3 \delta_{c}^{3}-5 \delta_{c}+2\right)+\delta_{c} \alpha^{2} Q\left(-3 \delta_{c}^{2}-9 \delta_{c}+8\right)+3 \delta_{c}^{2} \alpha^{3}=0 .
\end{aligned}
$$

If there is only one solution within $(0, \alpha)$ then $D$ is convex in $Q$ when $Q \in\left(0, Q_{1}\right)$, and concave in $Q$ when $Q \in\left[Q_{1}, \alpha\right)$. If there are three solutions within $(0, \alpha)$, then $D$ is convex in $Q$ when $Q \in\left(0, Q_{1}\right) \cup\left[Q_{2}, Q_{3}\right)$ and concave in $Q$ when $Q \in\left[Q_{1}, Q_{2}\right) \cup\left[Q_{3}, \alpha\right)$.

\section{Proof. See the appendix.}

Proposition 1 has the following implications. If consumers become more patient, they will delay the purchase decision. Thus, the demand will decrease. The high impact 
intensity means a large installed base and strong influence of predecessors on the imitators; thus, the demand will increase. For influencers, the higher the price, the higher the quality. Thus, the demand in the first period will increase. However, imitators will be more sensitive to the price if the influence from predecessors is not large enough. Thus, the second-period demand will decrease as a result of a high price. Finally, the third statement gives a guideline regarding how the innovation level affects the demand. In particular, we can obtain the condition under which the total demand increases quickly as the innovation level changes and choose a proper innovation level in practice.

4.2. Optimal Discounts in the Two-Advance-Selling-Discount Model. By considering the profit function given in equation (6), the retailer's problem can be formulated as

$$
\begin{aligned}
\pi_{R}\left(\delta_{2}\right)= & \left(\delta_{2} p-\delta_{1} r\right) \frac{Q-\delta_{2} p+\delta_{c}(p-Q)}{Q+\delta_{c}(\alpha-Q)} \\
& +(p-r) \frac{\delta_{2} p(Q-\alpha)+Q(\alpha-p)}{Q\left(Q+\delta_{c}(\alpha-Q)\right)} .
\end{aligned}
$$

Similarly, by considering the profit function given in equation (7), along with the financial constraint, the supplier's problem can be formulated as

$$
\begin{aligned}
\pi_{S}\left(\delta_{1}\right)= & \delta_{1} r \frac{Q-\delta_{2} p+\delta_{c}(p-Q)}{Q+\delta_{c}(\alpha-Q)} \\
& +r \frac{\delta_{2} p(Q-\alpha)+Q(\alpha-p)}{Q\left(Q+\delta_{c}(\alpha-Q)\right)}-\xi Q^{2},
\end{aligned}
$$

subject to

$$
\xi Q^{2} \leq \gamma \delta_{1} r \frac{Q-\delta_{2} p+\delta_{c}(p-Q)}{Q+\delta_{c}(\alpha-Q)} .
$$

The following proposition characterizes the supplier's and the retailer's optimal discounts which solve their problems given in equations (15) and (16).

Proposition 2. If $(\gamma / \xi) \geq 8 Q^{4}\left(Q+\delta_{c}(\alpha-Q)\right) /\left(\left(1-\delta_{c}\right)\right.$ $\left.Q^{2}+\delta_{c} p Q+p(\alpha-Q)\right)\left(\left(1-\delta_{c}\right) Q^{2}+\delta_{c} p Q+(2 r-p)(Q-\right.$ $\alpha)$ ), then the optimal advance selling discounts, which we denote by $\delta_{1}^{*}$ and $\delta_{2}^{*}$, respectively, are given by

$$
\begin{aligned}
& \delta_{1}^{*}=\frac{Q^{2}+2 r Q-2 r \alpha+p(\alpha-Q)+\delta_{c} Q(p-Q)}{2 r Q}, \\
& \delta_{2}^{*}=\frac{3\left(1-\delta_{c}\right) Q^{2}+3 \delta_{c} p Q+p(Q-\alpha)}{4 p Q} .
\end{aligned}
$$

$\delta_{1}^{*}$ is decreasing in $\delta_{c}$ and $r$, and increasing in $p$ and $Q$. If $2 r>p$, then $\delta_{1}^{*}$ is decreasing in $\alpha$; otherwise $\delta_{1}^{*}$ is increasing in $\alpha . \delta_{2}^{*}$ is decreasing in $\delta_{c}, \alpha$, and $p$ and increasing in $Q$.

On the contrary, if $(\gamma / \xi)<8 Q^{4}\left(Q+\delta_{c}(\alpha-Q)\right) /\left(\left(\left(1-\delta_{c}\right)\right.\right.$ $\left.Q^{2}+\delta_{c} p Q+p(\alpha-Q)\right)\left(\left(1-\delta_{c}\right) Q^{2}+\delta_{c} p Q+(2 r-p)\right.$ $(Q-\alpha)))$, then the financial constraint (17) does not hold.
Proof. See the appendix.

Proposition 2 describes the optimal solution to the supplier's and the retailer's problems when they prepare to launch a new product facing strategic consumers under social influence. If $\gamma / \xi$ is not less than the threshold, that is, the supplier is highly informationally transparent or has a low development cost coefficient, then the financial constraint (17) is not binding; in that case, $\left(\delta_{1}^{*}, \delta_{2}^{*}\right)$ is the global optimal solution. If $\gamma / \xi$ is lower than the threshold, that is, the supplier is badly informationally transparent, or has a higher development cost coefficient, then the supplier cannot meet its financial constraint to begin the production. On substituting $\delta_{1}^{*}$ and $\delta_{2}^{*}$ into equations (15) and (16), we can obtain the retailer's and the supplier's optimal profits, which are denoted by $\pi_{R}^{*}$ and $\pi_{S}^{*}$, respectively. Let $\pi_{D}^{*}$ denote the total profit.

Also, Proposition 2 sheds light on how exogenous parameters affect the optimal advance selling discounts. With a higher regular contract price or a higher regular selling price, the upstream firms must provide a lower discount price (smaller $\delta_{1}^{*}$ and $\delta_{2}^{*}$ ) to obtain precommitted orders and enough money from consumers to begin production. However, a higher regular selling price means the firms benefit more from consumers. As a result, the supplier will provide a higher discount price (bigger $\delta_{1}^{*}$ ) when the selling price is high. Since $\delta_{c}$ can be regarded as a measure of the consumers' patience, when consumers become more patient, the upstream firms have more incentive to provide a lower discount price (smaller $\delta_{1}^{*}$ and $\delta_{2}^{*}$ ). Consider consumers whose sensitivity to the innovation level is larger than the sensitivity to the price, i.e., they are willing to pay for a product with higher innovation levels. Thus, the upstream firms will provide higher discount prices (bigger $\delta_{1}^{*}$ and $\delta_{2}^{*}$ ) to achieve more profit. Because the higher impact intensity of predecessors can lead to a higher demand in the second period, the retailer will have more incentive to provide a lower discount price (smaller $\delta_{2}^{*}$ ) to attract more influencers.

4.3. Two-Advance-Selling-Discount Model vs. Base Case and Centralized Case. Given total demand $D_{0}$ in the base case, equations (2) and (3) can be rewritten as

$$
\begin{aligned}
\pi_{0}^{R} & =(p-r) \frac{Q-p}{Q}, \\
\pi_{0}^{S} & =r \frac{Q-p}{Q}-\xi Q^{2} .
\end{aligned}
$$

Also, the supply chain's total profit can be written as $\pi_{0}=p(Q-p) / Q-\xi Q^{2}$.

By considering the profit function given in equation (4), the central planner's problem can be formulated as

$$
\begin{aligned}
\pi_{C}\left(\delta_{2}\right)= & p \frac{\delta_{2} p(Q-\alpha)+Q(\alpha-p)}{Q\left(Q+\delta_{c}(\alpha-Q)\right)} \\
& +\delta_{2} p \frac{Q-\delta_{2} p+\delta_{c}(p-Q)}{Q+\delta_{c}(\alpha-Q)}-\xi Q^{2},
\end{aligned}
$$


subject to

$$
\xi Q^{2} \leq \gamma \delta_{2} p \frac{Q-\delta_{2} p+\delta_{c}(p-Q)}{Q+\delta_{c}(\alpha-Q)} .
$$

The following proposition describes the optimal advance selling discount in the centralized system.

Proposition 3. If $(\gamma / \xi) \geq 4 Q^{4}\left(Q+\delta_{c}(\alpha-Q)\right) /\left(\left(\left(1-\delta_{c}\right)\right.\right.$ $\left.\left.Q^{2}+\delta_{c} p Q\right)^{2}-p^{2}(\alpha-Q)^{2}\right)$, then the optimal advance selling discount, denoted by $\delta_{2}^{C *}$, is

$$
\delta_{2}^{C *}=\frac{\left(1-\delta_{c}\right) Q^{2}+\delta_{c} p Q+p(Q-\alpha)}{2 p Q} .
$$

$\delta_{2}^{C *}$ is decreasing in $\delta_{c}, \alpha$, and $p$ and increasing in $Q$.

On the contrary, if $(\gamma / \xi)<4 Q^{4}\left(Q+\delta_{c}(\alpha-Q)\right) /$ $\left(\left(\left(1-\delta_{c}\right) Q^{2}+\delta_{c} p Q\right)^{2}-p^{2}(\alpha-Q)^{2}\right)$, then the financial constraint (21) does not hold.

Proof. See the appendix.

Proposition 3 demonstrates that if $\gamma / \xi \geq 4 Q^{4}\left(Q+\delta_{c}(\alpha-\right.$ $Q)) /\left(\left(\left(1-\delta_{c}\right) Q^{2}+\delta_{c} p Q\right)^{2}-p^{2}(\alpha-Q)^{2}\right)$, then $\delta_{2}^{C *}$ is the global optimal solution in the centralized system. However, if $\quad(\gamma / \xi)<4 Q^{4}\left(Q+\delta_{c}(\alpha-Q)\right) /\left(\left(\left(1-\delta_{c}\right) Q^{2}+\delta_{c} \quad p Q\right)^{2}\right.$ $\left.-p^{2}(\alpha-Q)^{2}\right)$, then there will not be sufficient funds to begin the production in the first period. Propositions 2 and 3 show that both the supplier and the central planner are risk-averse. Only when the income from the first period is larger than the total cost do they invest in a new innovation level. On substituting $\delta_{2}^{C *}$ into equation (20), we can obtain the optimal profit, which is denoted by $\pi_{C}^{*}$.

In terms of firms' profits, we compare the base case with the centralized case first and then compare the TASD model with the base case and the centralized case. The following proposition characterizes the comparisons.

\section{Proposition 4}

(i) The optimal profit $\pi_{C}^{*} \geq \pi_{0}=p(Q-p) / Q-\xi Q^{2}$

(ii) The following hold: $\pi_{R} \geq \pi_{0}^{R}=(p-r)(Q-p) / Q$ and $\pi_{S} \geq \pi_{0}^{S}=r(Q-p) / Q-\xi Q^{2}$

Proof. See the appendix.

Proposition 4 illustrates that when the central planner optimizes its profit over $\delta_{2}$, the optimal supply chain profit is at least as much as that in the base case. Moreover, in the decentralized supply chain, the TASD model produces a Pareto-improved result; that is, both the supplier and the retailer can obtain higher profits compared with the base case.

In the decentralized supply chain, the total profit can be written as

$$
\pi_{D}=\pi_{R}+\pi_{S}
$$

By substituting equations (15) and (16) into (23), the decentralized supply chain's profit can be formulated as follows:

$$
\begin{aligned}
\pi_{D}\left(\delta_{2}\right)= & \delta_{2} p \frac{Q-\delta_{2} p+\delta_{c}(p-Q)}{Q+\delta_{c}(\alpha-Q)} \\
& +p \frac{\delta_{2} p(Q-\alpha)+Q(\alpha-p)}{Q\left(Q+\delta_{c}(\alpha-Q)\right)}-\xi Q^{2}
\end{aligned}
$$

The optimal advance selling discount that the retailer offers to consumers is

$$
\delta_{2}^{D *}=\frac{\left(1-\delta_{c}\right) Q^{2}+\delta_{c} p Q+p(Q-\alpha)}{2 p Q} .
$$

Observing equation (20), if $\delta_{2}=\delta_{2}^{D *}=\delta_{2}^{C *}$, then the discount contract $\left(\delta_{1}, \delta_{2}\right)$ can coordinate the decentralized supply chain. However, $\delta_{2}^{*}>\delta_{2}^{D *}=\delta_{2}^{C *}$, which means that the retailer will not set $\delta_{2}=\delta_{2}^{C *}$. Therefore, the whole supply chain will not achieve the maximum profit.

Proposition 5. Since $\delta_{2}^{*}>\delta_{2}^{C *}$, the TASD model will never coordinate the supply chain in a decentralized system.

Although $\delta_{1}^{*}$ and $\delta_{2}^{*}$ enable the supplier and the retailer to maximize their profits, using these two discounts is not conducive to increasing the total profit of the supply chain.

\section{Two-Advance-Selling-Discount Model with a Minimum Order Quantity}

In the previous model, we characterized the optimal advance selling strategies under social influence when the supplier and the retailer launch a new product. As discussed after Proposition 5, the optimal advance selling discounts $\delta_{1}^{*}$ and $\delta_{2}^{*}$ cannot coordinate the supply chain. In this section, we explore a method to improve the performance of the supply chain. Since the new product has quality uncertainty, it is necessary for the upstream enterprises to encourage consumers to purchase in advance under social influence. However, for fear that there will be too few orders to begin the production, the upstream enterprises usually set a minimum order quantity $D_{m}$ as a qualifier for the downstream enterprises to enjoy a discount price.

In this section, we extend our model to analyze the influence of the minimum order quantity on the supply chain. We use the subscript $m$ to denote the case in which the supplier sets a minimum order quantity $D_{m}$ as a qualifier for the retailer to obtain the discount price. If $D_{m 1} \geq D_{m}$, then the optimal decision is the same as the results in Section 4. However, if $D_{m 1}<D_{m}$, then the retailer must order at least $D_{m}$ in the first period to obtain the discount price. If $D_{m 2} \geq D_{m}-D_{m 1}$, then the retailer will order $D_{m 2}-\left(D_{m}-\right.$ $\left.D_{m 1}\right)$ in the second period additionally. If $D_{m 2}<D_{m}-D_{m 1}$, then the supplier will salvage surplus products at $b$ per unit. In this case, buyback contracts eliminate the salvage market. Thus, the retailer is willing to place an advance purchase order and offer consumers a discount price. Also, consumers are motivated to purchase in the first period rather than wait until the product is out of date. Therefore, the product lifecycle is shortened, and the product will be updated continuously. 
If $D_{m}>D_{m 1}$ and $D_{m 2} \geq D_{m}-D_{m 1}$, then the retailer will order $D_{m}$ in the first period and order an additional $D_{m 2}-$ $\left(D_{m}-D_{m 1}\right)$ in the second period. Thus, the retailer's profit function is

$$
\pi_{m R}\left(\delta_{m 2}\right)=\left(\delta_{m 2} p-r\right) D_{m 1}+(p-r) D_{m 2}+\left(r-\delta_{m 1} r\right) D_{m} .
$$

The supplier's profit function is

$$
\pi_{m S}\left(\delta_{m 1}\right)=\left(\delta_{m 1} r-r\right) D_{m}+r\left(D_{m 1}+D_{m 2}\right)-\xi Q^{2},
$$

subject to

$$
\xi Q^{2} \leq \gamma \delta_{m 1} r D_{m} .
$$

Because the optimal advance selling discount $\delta_{m 2}^{*}>\delta_{2}^{C *}$, the minimum order quantity contract cannot coordinate the supply chain. On substituting $\delta_{m 1}^{*}, \delta_{m 2}^{*}$, and $D_{m}^{*}$ into equations (26) and (27), we obtain the retailer's and the supplier's optimal profits, which are denoted by $\pi_{m R}^{*}$ and $\pi_{m S}^{*}$, respectively. Let $\pi_{m}^{*}$ denote the total profit.

We use the subscript $b$ to denote the case in which the supplier sets a minimum order quantity $D_{b}$ and salvages surplus products remaining at the end of the second period. If $D_{b}>D_{b 1}$ and $D_{b 2}<D_{b}-D_{b 1}$, then the retailer will order $D_{b}$ in the first period and the supplier will salvage $D_{b}-$ $\left(D_{b 1}+D_{b 2}\right)$ at the end of the second period. Thus, the retailer's profit is

$$
\pi_{b R}\left(\delta_{b 2}\right)=\left(\delta_{b 2} p-b\right) D_{b 1}+(p-b) D_{b 2}+\left(b-\delta_{b 1} r\right) D_{b} .
$$

The supplier's profit function is

$$
\pi_{b S}\left(\delta_{b 1}\right)=\delta_{b 1} r D_{b}-b\left(D_{b}-D_{b 1}-D_{b 2}\right)-\xi Q^{2},
$$

subject to

$$
\xi Q^{2} \leq \gamma \delta_{b 1} r D_{b} .
$$

Because the optimal advance selling discount $\delta_{b 2}^{*}>\delta_{2}^{C *}$, the buyback contract cannot coordinate the supply chain. On substituting $\delta_{b 1}^{*}, \delta_{b 2}^{*}$, and $D_{b}^{*}$ into equation (29) and (30), we obtain the retailer's and the supplier's profits, which are denoted by $\pi_{b R}^{*}$ and $\pi_{b S}^{*}$, respectively. Let $\pi_{b}^{*}$ denote the total profit. The following lemma characterizes the optimal advance selling discounts and the optimal minimum order quantity.

\section{Lemma 3}

(i) If $D_{m}>D_{m 1}$ and $D_{m 2} \geq D_{m}-D_{m 1}$, then the optimal combined contract $\left(\delta_{m 1}^{*}, D_{m}^{*}\right)$ and the optimal advance selling discount $\delta_{m 2}^{*}$ are

$$
\begin{aligned}
& \delta_{m 1}^{*}=1, \\
& D_{m}^{*}=\frac{\xi Q^{2}}{r \gamma}, \\
& \delta_{m 2}^{*}=\frac{\left(1-\delta_{c}\right) Q^{2}+\delta_{c} p Q+p(Q-\alpha)+r \alpha}{2 p Q} .
\end{aligned}
$$

$\delta_{m 2}^{*}$ is decreasing in $\delta_{c}, \alpha$, and $p$, and increasing in $Q$ and $r$.

Furthermore, if $\left(1-\delta_{c}\right)(Q-p) Q+(p-2 r) \alpha>0$, then $\delta_{2}^{C *}<\delta_{m 2}^{*}<\delta_{2}^{*}$. Also, $\pi_{m}^{*}>\pi_{D}^{*}$ and $\pi_{m S}^{*}>\pi_{S}^{*}$. Moreover, if the condition $3 Q^{4}+3 p^{2}(Q-\alpha)^{2}+$ $4 r^{2} \alpha^{2}+3(p-Q)^{2} Q^{2} \delta_{c}^{2} \geq 8 Q^{2} r \alpha+2 p(Q-\alpha)\left(3 Q^{2}-\right.$ $4 r \alpha)+2(p-Q) Q\left(-3 Q^{2}+3 p(Q-\alpha)+4 r \alpha\right) \delta_{c}$ holds, then $\pi_{m R}^{*}>\pi_{R}^{*}$.

(ii) If $D_{b}>D_{b 1}$ and $D_{b 2}<D_{b}-D_{b 1}$, then the optimal combined contract $\left(\delta_{b 1}^{*}, D_{b}^{*}\right)$ and the optimal advance selling discount $\delta_{b 2}^{*}$ are

$$
\begin{aligned}
& \delta_{b 1}^{*}=1, \\
& D_{b}^{*}=\frac{\xi Q^{2}}{r \gamma}, \\
& \delta_{b 2}^{*}=\frac{\left(1-\delta_{c}\right) Q^{2}+\delta_{c} p Q+p(Q-\alpha)+b \alpha}{2 p Q} .
\end{aligned}
$$

$\delta_{b 2}^{*}$ is decreasing in $\delta_{c}, \alpha$, and $p$, and increasing in $Q$ and $b$. Furthermore, if $\left(1-\delta_{c}\right)(Q-p) Q+(p-2 b) \alpha>0$, then $\delta_{2}^{C *}<\delta_{b 2}^{*}<\delta_{2}^{*}$. Also, $\pi_{b}^{*}>\pi_{D}^{*}$.

Proof. See the appendix.

Lemma 3 states that although the minimum order quantity contract and the buyback contract cannot coordinate the supply chain, they can improve supply chain efficiency compared with the pure strategy $\left(\delta_{1}^{*}, \delta_{2}^{*}\right)$. Obviously, if $D_{m}>D_{m 1}$ and $D_{m 2} \geq D_{m}-D_{m 1}$, then the supplier's profit increases, and when the exogenous parameters satisfy the condition mentioned in Lemma 3 (i), the retailer's profit will increase also.

Corollary 1. If the exogenous parameters satisfy the condition that (i) $\partial\left(\pi_{m}^{*}-\pi_{D}^{*}\right) / \partial Q>0$ and $\partial^{2}\left(\pi_{m}^{*}-\pi_{D}^{*}\right) / \partial Q^{2}>0$ or (ii) $\partial\left(\pi_{b}^{*}-\pi_{D}^{*}\right) / \partial Q>0$ and $\partial^{2}\left(\pi_{b}^{*}-\pi_{D}^{*}\right) / \partial Q^{2}>0$, then for a higher innovation level, the supplier should set the minimum order quantity at the beginning of the first period. However, for a lower innovation level, it is advisable for the enterprises to determine the optimal advance selling discounts stated in Proposition 2.

Corollary 1 illustrates the properties of the minimum order quantity. Although setting a minimum quantity can increase the total profit, it is not completely applicable in practice. For a new product with a higher innovation level, the total profit increases quickly as the innovation level increases. Thus, for a product that has a low demand and is difficult for consumers to accept, setting a minimum order quantity can improve the supply chain efficiency. However, for a product that has a high demand and is easily accepted by consumers, the total profit increases slowly as the innovation level increases when the supplier sets a minimum order quantity. Thus, the enterprises should make their decisions according to Proposition 2. In this way, the total demand will be stimulated by discount prices, and the retailer has more motivation to place precommitted orders in order to benefit from a discount price. 


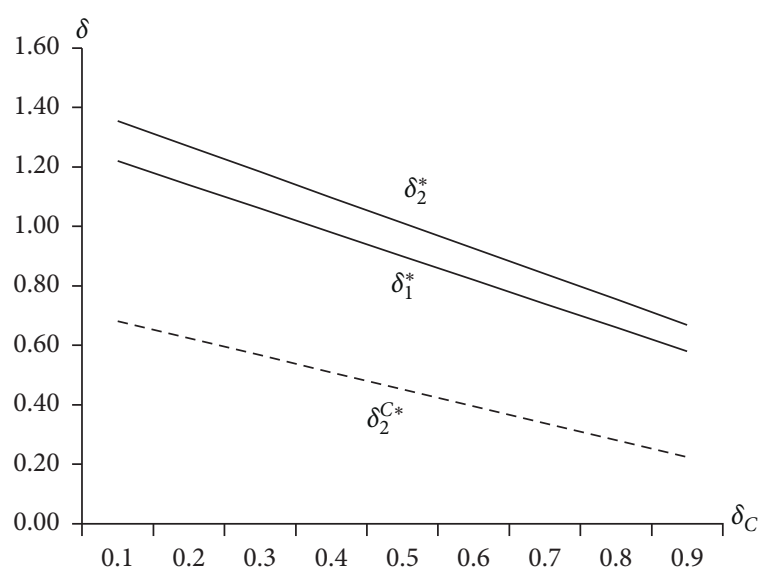

(a)

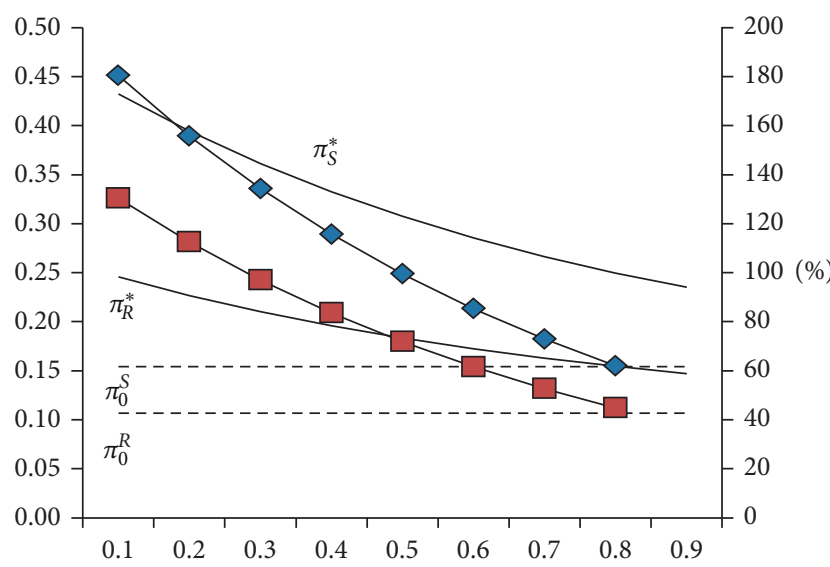

(c)

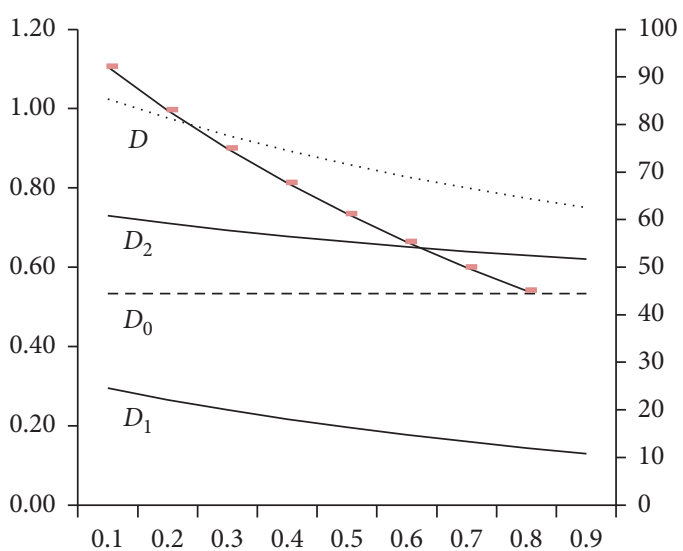

(b)

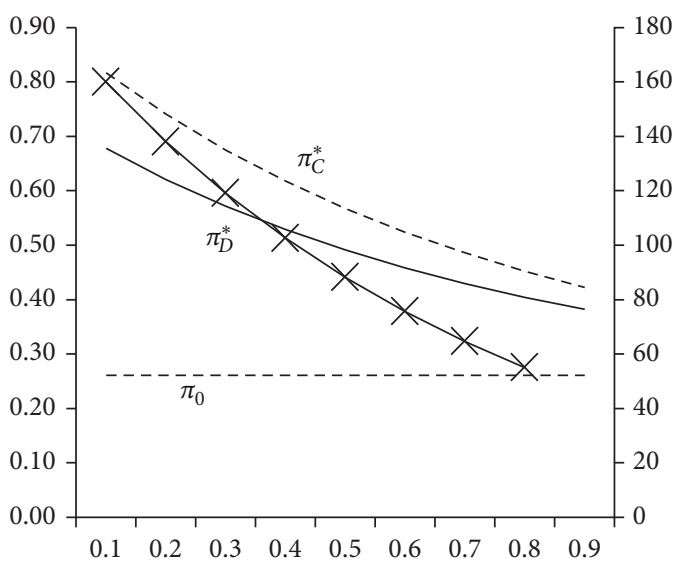

(d)

Figure 2: Influence of the consumer discount factor on the advance selling strategy. The percentage line represents the demand improvement and the profit improvement of the TASD model compared with the base case.

\section{Numerical Examples}

The purpose of this section is to clarify our results and numerically compare the abovementioned conclusions. The experimental parameters are $\delta_{c}, Q, \alpha, p$, and $b$, while the other parameters remain fixed. As done in previous numerical examples (e.g., $[33,34])$, the numerical values have been calculated assuming $b=0.25 \mathrm{p}$. First, we compare the TASD model with the base case and the centralized case when there is no constraint on the precommitted order quantity.

We first investigate the influence of the consumer discount factor. From Figure 2, we can know that as consumers become more patient, the upstream firms should provide lower discount prices to stimulate consumption. Compared with the base case, the more impulsive consumers are, the faster the demands and profits grow. Thus, it is more profitable for firms to adopt the TASD model. Figure 3 indicates that if the innovation level is high, the firms will provide high discounts and the demand will decrease. However, the changes in demand are not obvious, and with the improvement of innovation level, the growth rate of supplier's profit compared with the base case is much larger than that of the retailer's profit. Thus, the supplier may be enthusiastic about improving the innovation level and adopting the advance selling strategy.

Figure 4 illustrates the influence of predecessors. High impact intensity requires a large installed base. Thus, firms will provide deep advance selling discounts and then attract high demands in the first and second periods. In the presence of social influence, the interaction between consumers greatly increases the total demand compared with the base case where there is no advance selling discount and increases profits for both the supplier and the retailer.

Finally, Figure 5 shows the influence of the regular selling price that the retailer quotes to consumers. When the regular selling price is high, the retailer needs to provide a deep discount to obtain precommitted orders. However, for the supplier, a high selling price means the retailer can obtain more profit from consumers. Thus, the supplier will raise the discount to capture most of the profit. As the price gets higher and higher, though the supplier's profit decreases, the supplier's growth rate compared with the base case is much faster than that of the retailer's profit in the TASD model. Moreover, the difference of the total demand and the difference of the total profit between these two 


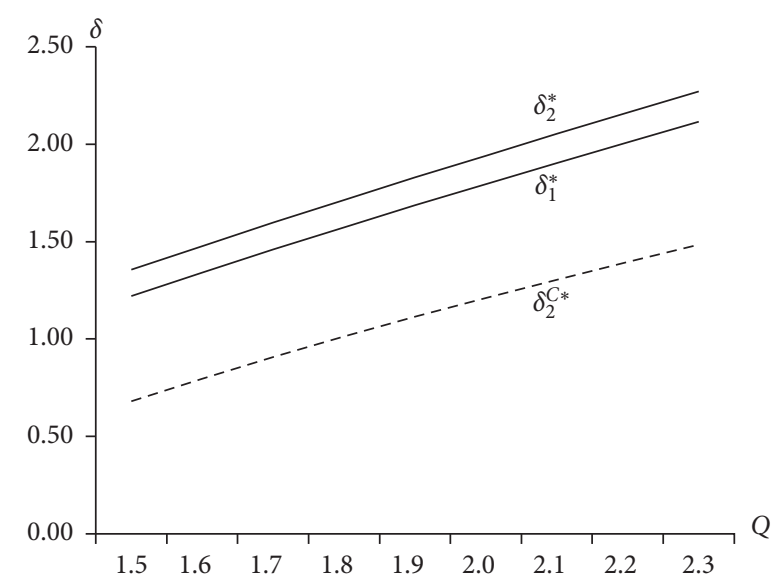

(a)

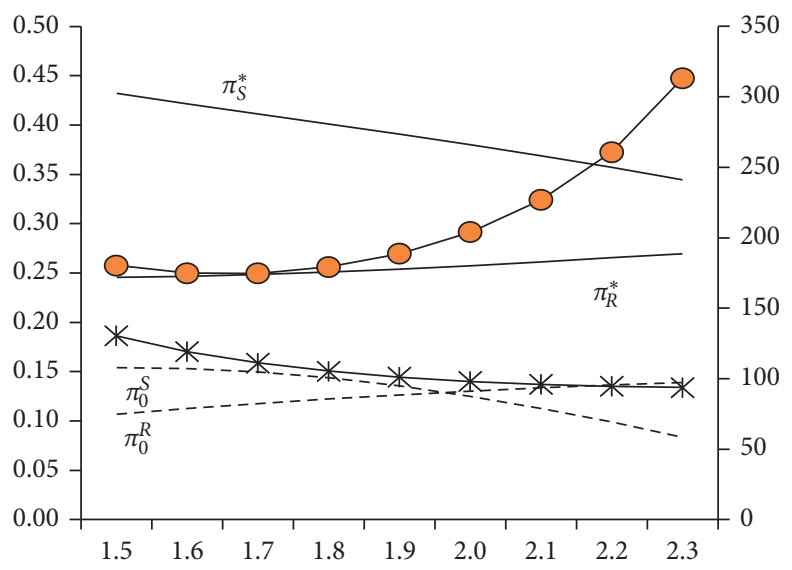

(c)

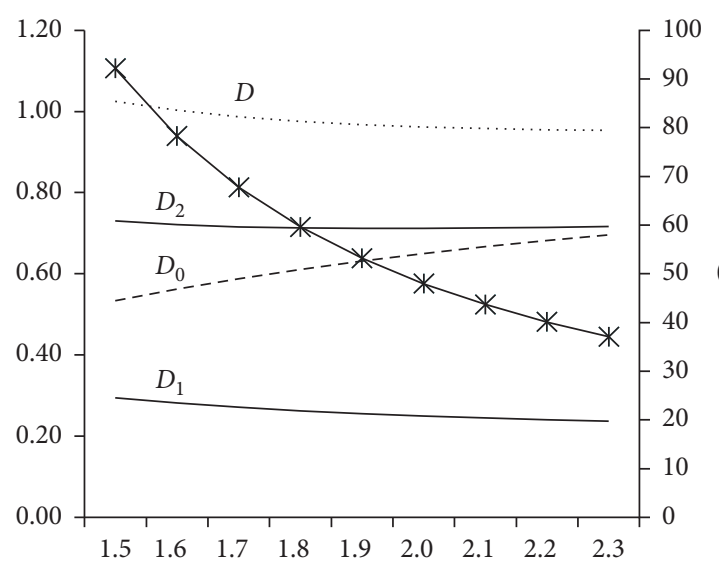

(b)

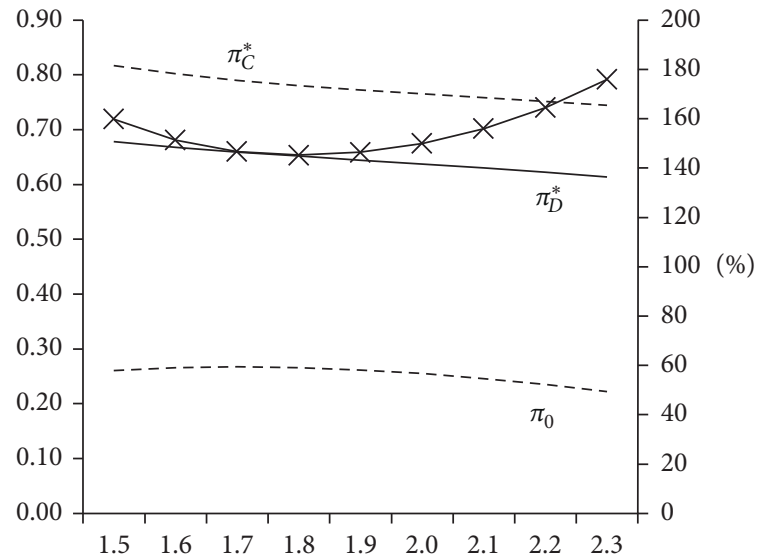

(d)

Figure 3: Influence of the innovation level on the advance selling strategy. The percentage line represents the demand improvement and the profit improvement of the TASD model compared with the base case.

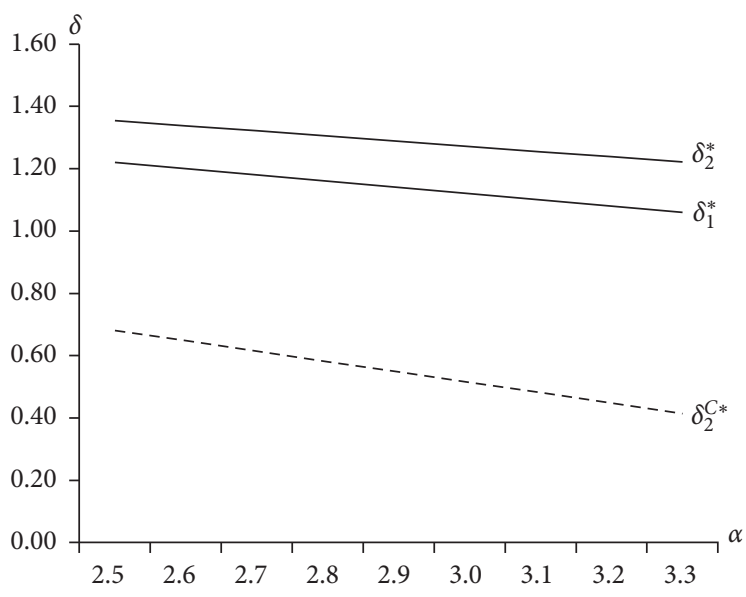

(a)

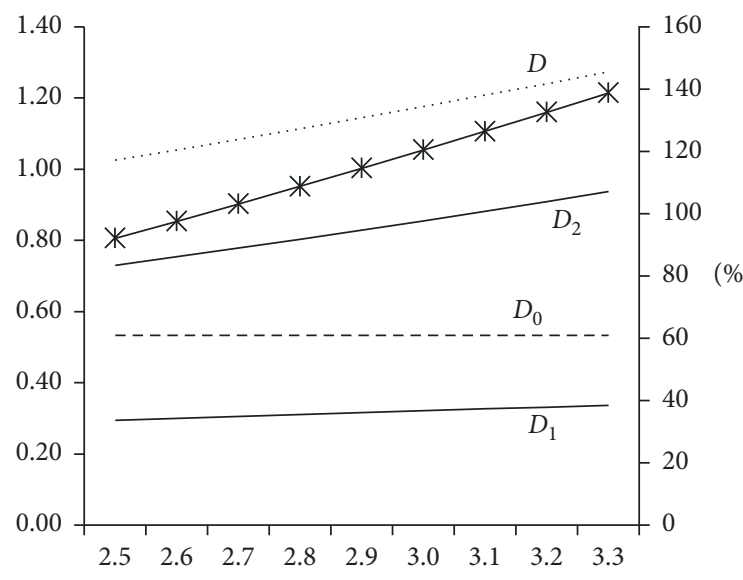

(b)

Figure 4: Continued. 


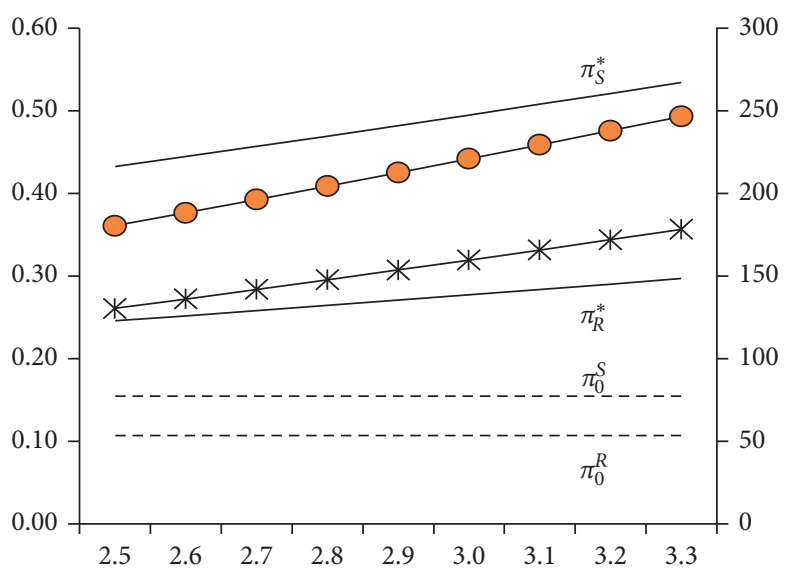

(c)

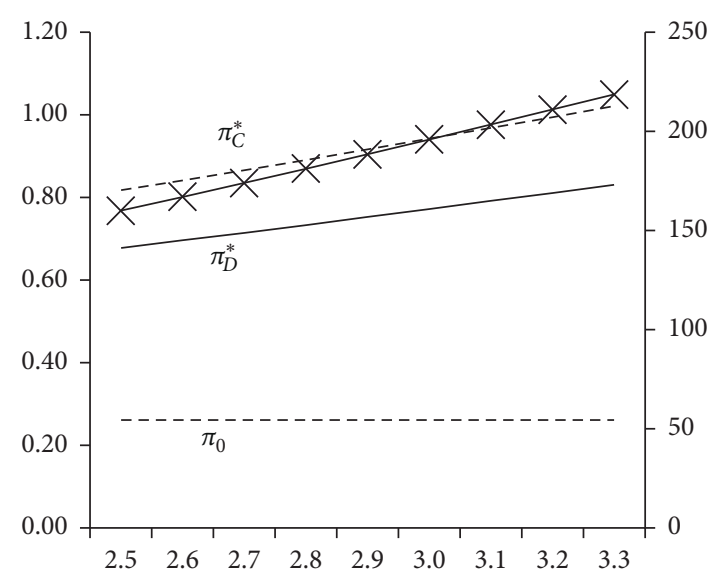

(d)

FIGURE 4: Influence of the impact intensity on the advance selling strategy. The percentage line represents the demand improvement and the profit improvement of the TASD model compared with the base case.

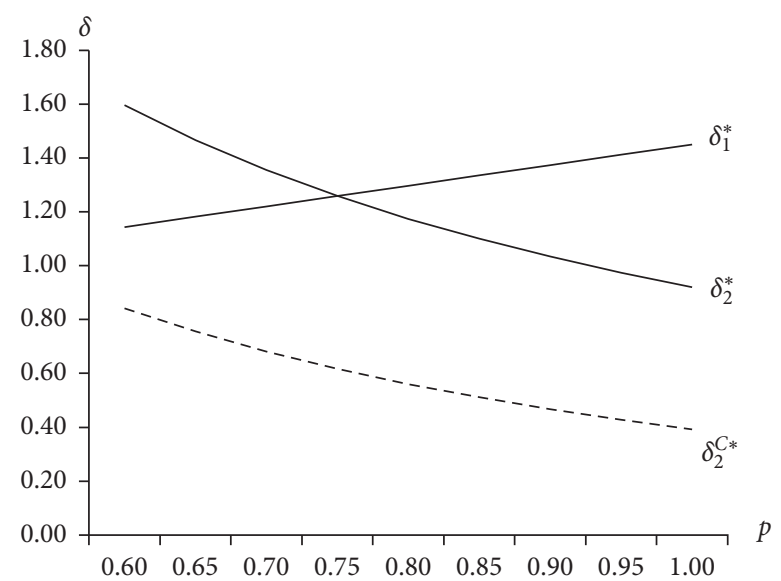

(a)

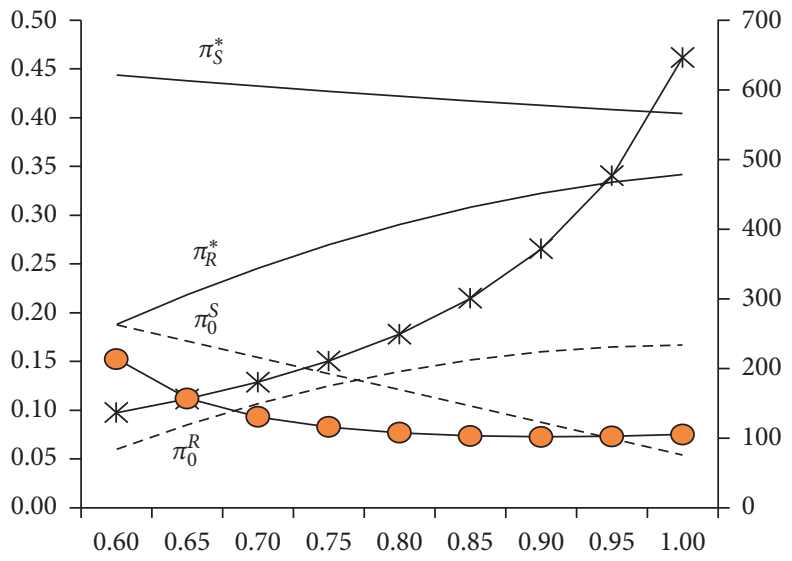

(c)

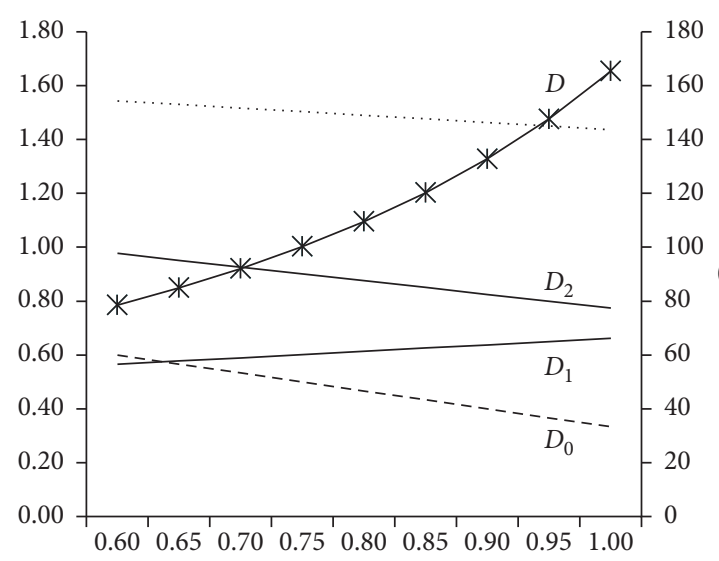

(b)

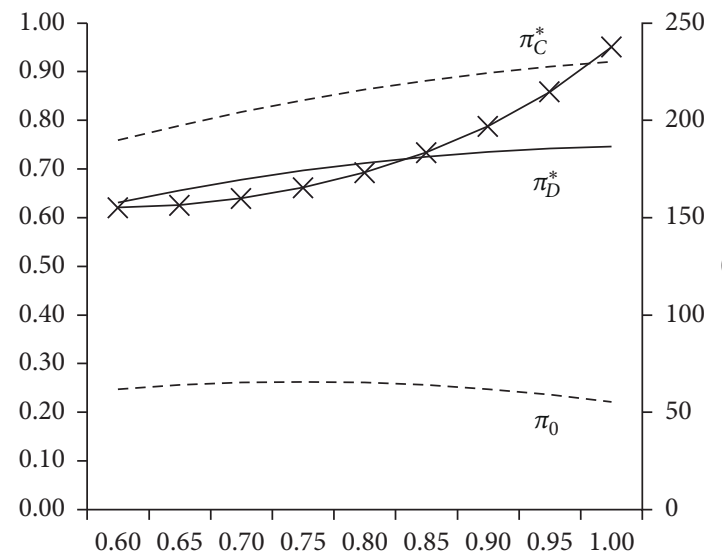

(d)

FIGURE 5: Influence of the regular selling price on the advance selling strategy. The percentage line represents the demand improvement and the profit improvement of the TASD model compared with the base case.

models increase, so it is beneficial for suppliers to adopt the TASD model. Meanwhile, as the selling price increases, the effects of the innovation level and the impact intensity are relatively weak. For the influencers, the higher the price, the higher the quality. Thus, the demand in the first period will increase. However, consumers who are less sensitive to the 
innovation level or the influence from predecessors will pay more attention to the utility coming from the regular selling price. Thus, the demand in the second period will decrease.

Additionally, for the five scenarios in our numerical study, it is obvious that the profits in the TASD model are larger than the profits in the base case, where there is no advance selling discount. Also, the advance selling discount $\delta_{2}^{*}$ in the decentralized case is bigger than the discount $\delta_{2}^{C *}$ in the centralized case. Thus, the TASD model cannot coordinate the supply chain. However, the difference between $\pi_{C}^{*}$ and $\pi_{D}^{*}$ is far less than the difference between $\pi_{C}^{*}$ and $\pi_{0}$. Thus, it is beneficial for firms to adopt the TASD model, by which they can maximize their profits.

Next, we compare the TASD model with the base case and the centralized case when there is a constraint on the precommitted order quantity. As above, we analyze how the experimental parameters affect the advance selling discounts and the profits. The process is the same as above. After calculating, we find that no matter how the parameters change, there are always certain scopes within which $\delta_{2}^{C *}<\delta_{m 2}^{*}<\delta_{2}^{*}$ and $\delta_{2}^{C *}<\delta_{b 2}^{*}<\delta_{2}^{*}$ hold. Moreover, in each scenario, the supplier and the retailer can obtain higher profits when participating in the minimum order quantity contract regardless of whether there is surplus product. Moreover, the total profit in the supply chain also increases. These results explain why the minimum order quantity contract is widely used in practice.

\section{Conclusions and Future Research}

This paper presents an analysis of the impact of the twoadvance-selling-discount model on a three-echelon supply chain when upstream enterprises launch a new product while facing strategic consumers under social influence. Recent research has highlighted the diffusion of a new product. However, such efforts have focused only on how consumers learn of the new product buying experiences from their peers, not on the decisions about whether to purchase the new product. Our paper reveals how social influence works when the advance selling policy is popular and adopted as the main promotion method.

We show that the imitators' utility increases with the number of influencers. In the presence of social influence, the lower an advance selling discount is, the more beneficial it is for consumers to purchase in the first period and the larger the imitators' utility will be. Furthermore, we characterize the property of sensitivity coefficients and demonstrate that the two-advance-selling discounts are decreasing in consumer's discount factor and the impact intensity of predecessors, while they are increasing in the innovation level. Besides this, the total demand is decreasing in consumer's discount factor and increasing in the impact intensity. We also obtain the condition under which the total demand increases quickly as the innovation level changes.

Another main consideration of our analysis is that we have incorporated the supplier's financial constraint into the TASD model. Specifically, we find that when the supplier is highly informationally transparent or has a lower development cost coefficient, the financial constraint may not be binding; in that case, the discounts described in Proposition 2 are the global optimal solution. Moreover, the TASD model can constitute a "win-win" situation: both the supplier and the retailer can obtain higher profits compared with the case where there is no discount. We also point out that the supplier and the retailer can increase their profits and improve the supply chain efficiency in the TASD model with a minimum order quantity. This suggests that although the TASD model cannot coordinate the supply chain, the supplier can maximize the supply chain's total profit by setting a minimum order quantity and salvaging surplus products when consumers' total demand is lower than the minimum order quantity.

Finally, we show a condition under which the upstream enterprises should impose a minimum order quantity as a qualifier for the downstream enterprises to receive a discount. For a product that has a low demand and is hard for consumers to accept, setting a minimum order quantity can improve the supply chain's efficiency. However, for a product that has a high demand and is easily accepted by consumers, the total profit increases slowly as the innovation level increases when the supplier sets a minimum order quantity; in this case, it is not advisable to impose a minimum order quantity.

There are limitations to our work, and we suggest several potential directions for future research. The first is associated with the innovation level. For tractability, we have assumed the innovation level is exogenous. However, it will be more instructive to study the case where the supplier determines the new product's innovation level and to explore the relationship between the innovation level and the advance selling discount. Second, we analyze only the case in which the buyback price is larger than the salvage value. However, when the buyback price is no more than the salvage value, the retailer has a decision to make about whether to participate in the buyback contract which is attached to the minimum order quantity contract, or to turn to the salvage market.

\section{Appendix}

Proof of Lemma 1. Let $U_{2}^{\prime}=\delta_{c}(\beta Q+\alpha x-p)$ denote the utility of the consumers who delay their purchase decisions until the second period. Let $x=1-y$ denote the number of consumers who purchase in the first period. We show that $\left(\partial U_{2}^{\prime} / \partial y\right)<0$, which implies that $U_{2}^{\prime}$ is increasing in $x$.

Proof of Lemma 2. The proof process is divided into four steps. First, we show that any purchase equilibrium must satisfy the first-period threshold policy. Second, we analyze the condition under which the threshold policy causes the delayed purchase. Third, we calculate the thresholds when the delayed purchase does not occur. Fourth, we find out how the threshold changes with the parameters. 
Step 1 . Define the utility difference between buying now and delaying buying given that $x$ consumers choose to purchase the new product in the first period by $\Delta(x)$. We have $\Delta(x)=\beta Q-\delta_{2} p-\delta_{c}(\beta Q+\alpha x-p)$. The derivative with respect to $\beta$ is given by $(\partial \Delta(x) / \partial \beta)=Q-\delta_{c} Q>0$. That is, $\Delta(x)$ is strictly increasing in $\beta$. Since the monotonicity holds for any arbitrary $x$ consumers, it follows that any equilibrium must satisfy the first-period threshold policy.

Step 2. Given that any equilibrium must satisfy the firstperiod threshold policy, we now consider the case in which no consumer purchases in the first period. To find the threshold, we first consider the highest preference (i.e., $\beta=1$ ). The utility of purchasing the product in the first period is $U_{1}=Q-\delta_{2} p$. If they all delay purchasing, then no consumer purchases in the first period and no reviews are generated in the first period. Thus, the utility of purchasing the product in the second period is $\delta_{c}(Q-p)$. Thus, the condition for delaying purchasing is $Q-\delta_{2} p<\delta_{c}(Q-p)$ or $\delta_{2}>\left(Q-\delta_{c}(Q-p)\right) / p$.

Step 3. If $\delta_{2} \leq\left(Q-\delta_{c}(Q-p)\right) / p$, then some consumers will purchase the new product in the first period.
Denote the consumers' utility of purchasing the new product in the first period by $U_{1}=\beta Q-\delta_{2} p$ and consumers' utility of purchasing the new product in the second period, conditional on consumers with $\beta \geq \beta_{1}$ choosing to purchase the new product in the first period, by $U_{2}^{\prime}=\delta_{c}\left(\beta Q+\alpha\left(1-\beta_{1}\right)-p\right)$. The indifference equation $U_{1}=U_{2}^{\prime}$ has only one solution $\beta_{1}=\left(\delta_{2} p+\delta_{c}(\alpha-p)\right) /\left(Q+\delta_{c}(\alpha-Q)\right)$. Since the imitators purchase the new product if and only if the utility from purchasing in the second period is nonnegative, we obtain $\beta_{2} Q+\alpha\left(1-\beta_{1}\right)-p=0$ or $\beta_{2}=\left(1-\delta_{c}\right)(p-\alpha) /\left(Q+\delta_{c}(\alpha-Q)\right)+\delta_{2} p \alpha /(Q(Q+$ $\left.\left.\delta_{c}(\alpha-Q)\right)\right)$.

Step 4. From Step 3, we know that $\beta_{1}=\left(\delta_{2} p+\delta_{c}(\alpha-\right.$ $p)) /\left(Q+\delta_{c}(\alpha-Q)\right)$ and $\beta_{2}=\left(1-\delta_{c}\right)(p-\alpha) /\left(Q+\delta_{c}\right.$ $(\alpha-Q))+\delta_{2} p \alpha /\left(Q\left(Q+\delta_{c}(\alpha-Q)\right)\right)$. To analyze how the thresholds change with the parameters, we calculate their first-order derivatives with regard to $\delta_{c}, \alpha, Q$, and p. This yields the following:

$$
\begin{aligned}
& \frac{\partial \beta_{1}}{\partial \delta_{c}}=\frac{\alpha((Q-p) Q+p(\alpha-Q))}{4 Q\left(Q+\delta_{c}(\alpha-Q)\right)^{2}}, \\
& \frac{\partial \beta_{1}}{\partial \alpha}=\frac{\delta_{c}^{2}(p-Q)+\delta_{c} Q-p}{4\left(Q+\delta_{c}(\alpha-Q)\right)^{2}}, \\
& \frac{\partial \beta_{1}}{\partial Q}=\frac{p Q\left(1-\delta_{c}\right)(\alpha-Q)+Q\left(1-\delta_{c}\right)\left(\alpha p-(\alpha-p) \delta_{c} Q\right)+\delta_{c} p Q^{2}}{\left(Q+\delta_{c}(\alpha-Q)\right)^{2}}, \\
& \frac{\partial \beta_{1}}{\partial p}=\frac{-\delta_{c} Q+Q-\alpha}{4 Q\left(Q+\delta_{c}(\alpha-Q)\right)}, \\
& \frac{\partial \beta_{2}}{\partial \delta_{c}}=\frac{\alpha^{2} Q(Q-p)+\alpha^{2} p(\alpha-Q)}{4 Q^{2}\left(Q+\delta_{c}(\alpha-Q)\right)^{2}}, \\
& \frac{\partial \beta_{2}}{\partial \alpha}=\frac{Q^{2}\left(1-\delta_{c}\right)^{2}(p-Q)+p\left(2\left(\delta_{c}^{2}-1\right) \alpha Q-\delta_{c} \alpha^{2}+\delta_{c} \alpha Q\left(\delta_{c}-1\right)\right)}{4 Q 2\left(Q+\delta_{c}(\alpha-Q)\right)^{2}} .
\end{aligned}
$$

It is clear that $\partial \beta_{1} / \partial \delta_{c}>0, \partial \beta_{1} / \partial \alpha<0, \partial \beta_{1} / \partial Q>0$, $\partial \beta_{1} / \partial p<0, \partial \beta_{2} / \partial \delta_{c}>0$, and $\partial \beta_{2} / \partial \alpha<0$.

Proof of Proposition 1. Because consumers are distributed uniformly over the preference line and each consumer is characterized by $\beta \in[-M, 1]$, their demands in the first and second periods are given by

$$
\begin{aligned}
& D_{1}=1-\beta_{1}, \\
& D_{2}=\beta_{1}-\beta_{2} .
\end{aligned}
$$

To analyze how demands change with the parameters, we calculate first-order derivatives with regard to $\delta_{c}, \alpha, Q$, and $p$, giving the following: 


$$
\begin{aligned}
& \frac{\partial D_{1}}{\partial \delta_{c}}=\frac{\alpha Q(p-Q)+\alpha p(Q-\alpha)}{4 Q\left(Q+\delta_{c}(\alpha-Q)\right)^{2}}, \\
& \frac{\partial D_{1}}{\partial \alpha}=\frac{\left(1-\delta_{c}\right)\left(p-\delta_{c} Q+\delta_{c} p\right)}{4\left(Q+\delta_{c}(\alpha-Q)\right)^{2}}, \\
& \frac{\partial D_{1}}{\partial Q}=\frac{\left(1-\delta_{c}\right) Q\left(p(Q-\alpha)-\delta_{c} p Q+\alpha\left(\delta_{c} Q-p\right)\right)}{4 Q^{2}\left(Q+\delta_{c}(\alpha-Q)\right)^{2}}, \\
& \frac{\partial D_{1}}{\partial p}=\frac{\delta_{c} Q-Q+\alpha}{4 Q\left(Q+\delta_{c}(\alpha-Q)\right)}, \\
& \frac{\partial D_{2}}{\partial \delta_{c}}=\frac{\alpha(Q-\alpha)((Q-P) Q+p(\alpha-Q))}{4 Q^{2}\left(Q+\delta_{c}(\alpha-Q)\right)^{2}}, \\
& \frac{\partial D_{2}}{\partial \alpha}=\frac{\left(1-\delta_{c}\right)\left(Q^{3}+2 p Q(\alpha-Q)\right)+\delta_{c} \alpha^{2} p}{4 Q^{2}\left(Q+\delta_{c}(\alpha-Q)\right)^{2}}, \\
& \frac{\partial D}{\partial p}=\frac{\partial \delta_{c} Q(Q-\alpha)+Q\left(\delta_{c} Q-\alpha\right)+\alpha^{2}-4 Q^{2}}{4 \delta_{c}}, \\
& \frac{\partial D}{\partial \alpha}=\frac{(\alpha+Q)(\alpha-3 Q)-3 \delta_{c} Q(\alpha-Q)}{4 Q(Q)}, \\
& \frac{\partial \delta^{2}\left(Q+\delta_{c}(\alpha-Q)\right)}{4-\alpha p(Q-\alpha)}, \alpha(Q-\alpha)((Q-P) Q+p(\alpha-Q)) \\
& 4 \delta^{2}\left(Q+\delta_{c}(\alpha-Q)\right)^{2}
\end{aligned}
$$

It is easy to determine that $\partial D_{1} / \partial \delta_{c}<0, \partial D_{1} / \partial \alpha>0$, $\partial D_{1} / \partial Q<0, \quad \partial D_{1} / \partial p>0, \quad \partial D_{2} / \partial \delta_{c}<0, \quad \partial D_{2} / \partial \alpha>0$, $\partial D / \partial \delta_{c}<0$, and $\partial D / \partial \alpha>0$. If $\alpha<3 Q$, then $\partial D_{2} / \partial p<0$. If $\alpha<2 Q$, then $\partial D / \partial p<0$. According to the first-order condition of consumers' total demand, we can write $\partial^{2} D / \partial Q^{2}$ as follows:

$$
\frac{\partial^{2} D}{\partial Q^{2}}=\frac{2\left(\left(\alpha Q^{4}-4 p Q^{4}\right)\left(1-\delta_{c}\right)^{3}+\alpha p\left(-3 Q^{3}\left(3 \delta_{c}+1\right)\left(1-\delta_{c}\right)^{2}\right)+3 \alpha Q^{2}\left(3 \delta_{c}^{3}-5 \delta_{c}+2\right)+\delta_{c} \alpha^{2} Q\left(-3 \delta_{c}^{2}-9 \delta_{c}+8\right)+3 \delta_{c}^{2} \alpha^{3}\right)}{4 Q^{4}\left(Q+\delta_{c}(\alpha-Q)\right)^{2}} .
$$

Assuming that $g(Q)=\left(\alpha Q^{4}-4 p Q^{4}\right)\left(1-\delta_{c}\right)^{3}+$ $\alpha p\left(-3 Q^{3}\left(3 \delta_{c}+1\right)\left(1-\delta_{c}\right)^{2}\right)+3 \alpha Q^{2}\left(3 \delta_{c}^{3}-5 \delta_{c}+2\right)+\delta_{c} \alpha^{2} Q$ $\left(-3 \delta_{c}^{2}-9 \delta_{c}+8\right)+3 \delta_{c}^{2} \alpha^{3}$, we observe that $g(0)>0$ and $g(\alpha)<0$. Let $Q_{i}(i=1,2,3,4)$ denote the solutions to the following equation:

$$
\begin{aligned}
& \left(\alpha Q^{4}-4 p Q^{4}\right)\left(1-\delta_{c}\right)^{3}+\alpha p\left(-3 Q^{3}\left(3 \delta_{c}+1\right)\left(1-\delta_{c}\right)^{2}\right) \\
& \quad+3 \alpha Q^{2}\left(3 \delta_{c}^{3}-5 \delta_{c}+2\right)+\delta_{c} \alpha^{2} Q\left(-3 \delta_{c}^{2}-9 \delta_{c}+8\right)+3 \delta_{c}^{2} \alpha^{3}=0
\end{aligned}
$$


If there is only one solution within the interval (e.g., $\left.Q_{1} \in(0, \alpha)\right)$, then $\mathrm{D}$ is convex in $Q$ when $Q \in\left(0, Q_{1}\right)$ and concave in $Q$ when $Q \in\left[Q_{1}, \alpha\right)$. If there are three solutions within the interval (e.g., $Q_{1}, Q_{2}, Q_{3} \in(0, \alpha)$ ), then $D$ is convex in $Q$ when $Q \in\left(0, Q_{1}\right) \cup\left[Q_{2}, Q_{3}\right)$ and concave in $Q$ when $Q \in\left[Q_{1}, Q_{2}\right) \cup\left[Q_{3}, \alpha\right)$.

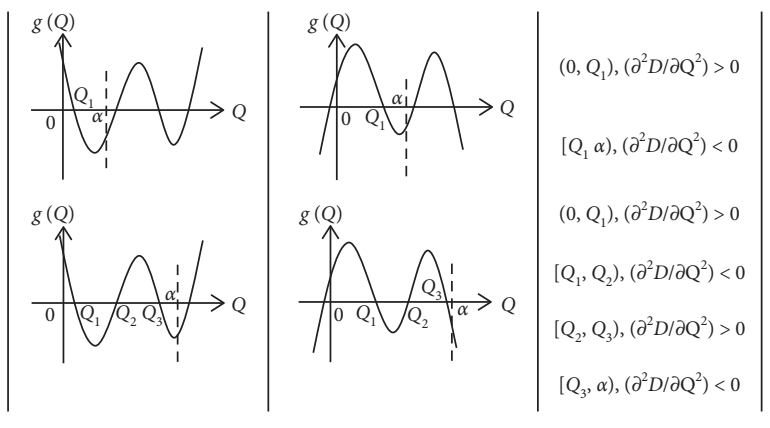

Proof of Proposition 2. Using equation (15), we can verify that $\partial^{2} \pi_{R} / \partial \delta_{2}^{2}<0$, which implies that the retailer's profit $\pi_{R}$ is concave in $\delta_{2}$. On substituting $\delta_{2}=\left(\left(1-\delta_{c}\right) Q^{2}+\delta_{c} p Q+\right.$ $\left.\delta_{1} r Q+(Q-\alpha)(p-r)\right) /(2 p Q)$ into equation (16), we know that $\partial^{2} \pi_{S} / \partial \delta_{1}^{2}<0$. Thus, the supplier's profit $\pi_{S}$ is concave in $\delta_{1}$. Then, we can obtain the optimal advance selling discount $\delta_{1}^{*}$ from $\partial \pi_{S} / \partial \delta_{1}=0$. We have $\delta_{2}^{*}-\left(Q-\delta_{c}(Q-p)\right) / p<0$, which means that $\delta_{2}^{*}$ satisfies the condition $\delta_{2} \leq\left(Q-\delta_{c}\right.$ $(Q-p)) / p$, which allows the retailer to determine the optimal advance selling discount to maximize its profit.

To analyze how exogenous parameters affect the optimal advance selling discounts, we calculate first-order derivatives with regard to $\delta_{c}, \alpha, Q, r$, and $p$ :

$$
\begin{aligned}
& \frac{\partial \delta_{1}^{*}}{\partial \delta_{c}}=\frac{p-Q}{2 r}, \\
& \frac{\partial \delta_{1}^{*}}{\partial \alpha}=\frac{p-2 r}{2 r Q}, \\
& \frac{\partial \delta_{1}^{*}}{\partial Q}=\frac{r Q^{2}\left(1-\delta_{c}\right)+r^{2} \alpha+r \alpha(r-p)}{Q\left(Q+\delta_{c}(\alpha-Q)\right)} \\
& \frac{\partial \delta_{1}^{*}}{\partial r}=\frac{\left(1-\delta_{c}\right)(Q-p) Q+p \alpha}{2 Q r^{2}}, \\
& \frac{\partial \delta_{1}^{*}}{\partial p}=\frac{\alpha-\left(1-\delta_{c}\right) Q}{2 r Q}, \\
& \frac{\partial \delta_{2}^{*}}{\partial \delta_{c}}=\frac{3 Q(p-Q)}{4 p Q}, \\
& \frac{\partial \delta_{2}^{*}}{\partial \alpha}=-\frac{1}{4 Q}, \\
& \frac{\partial \delta_{2}^{*}}{\partial Q}=\frac{3\left(1-\delta_{c}\right) Q^{2}+p \alpha}{4 p Q^{2}} \\
& \frac{\partial \delta_{2}^{*}}{\partial p}=-\frac{3\left(1-\delta_{c}\right) Q^{2}}{4 Q p^{2}} .
\end{aligned}
$$

It is easy to determine that $\partial \delta_{1}^{*} / \partial \delta_{c}<0, \partial \delta_{1}^{*} / \partial Q>0$, $\partial \delta_{1}^{*} / \partial r<0, \partial \delta_{1}^{*} / \partial p>0, \partial \delta_{2}^{*} / \partial \delta_{c}<0, \partial \delta_{2}^{*} / \partial \alpha<0, \partial \delta_{2}^{*} / \partial Q>0$, and $\partial \delta_{2}^{*} / \partial p<0$.

Proof of Proposition 3. From equation (20), we can verify that $\partial^{2} \pi_{C} / \partial \delta_{2}^{2}<0$. Thus, $\pi_{C}$ is concave in $\delta_{2}$. Also, we can obtain the optimal advance selling discount $\delta_{2}^{C *}$ from $\partial \pi_{C} / \partial \delta_{2}=0$. We have $\delta_{2}^{C *}-\left(Q-\delta_{c}(Q-p)\right) / p<0$, which means that $\delta_{2}^{C *}$ satisfies the condition $\delta_{2} \leq\left(Q-\delta_{c}(Q-\right.$ $p)) / p$, which allows the central planner to determine the optimal advance selling discount to maximize the supply chain's total profit. It is easy to determine that $\partial \delta_{2}^{C *} / \partial \delta_{c}<0$, $\partial \delta_{2}^{C *} / \partial \alpha<0, \partial \delta_{2}^{C *} / \partial Q>0$, and $\partial \delta_{2}^{C *} / \partial p<0$.

$$
\begin{aligned}
& \text { Proof of Proposition } 4 \\
& \begin{aligned}
& \pi_{C}^{*}-\pi_{0}=\frac{\left(Q^{2}+p(\alpha-Q)+\delta_{c} Q(p-Q)\right)^{2}}{4 Q^{2}\left(Q+\delta_{c}(\alpha-Q)\right)}, \\
& \pi_{R}-\pi_{0}^{R}=\frac{\left((p-r)(Q-\alpha)+\delta_{1} r Q-\delta_{2} p Q\right)\left(\left(\delta_{c}-1\right) Q+\left(\delta_{2}-\delta_{c}\right) p\right)}{Q\left(Q+\delta_{c}(\alpha-Q)\right)}, \\
& \pi_{S}-\pi_{0}^{S}=\frac{r\left(Q-\delta_{1} Q-\alpha\right)\left(\left(\delta_{c}-1\right) Q+\left(\delta_{2}-\delta_{c}\right) p\right)}{Q\left(Q+\delta_{c}(\alpha-Q)\right)} .
\end{aligned}
\end{aligned}
$$

Obviously, $\pi_{C}^{*}-\pi_{0}>0, \pi_{R}-\pi_{0}^{R}>0$, and $\pi_{S}-\pi_{0}^{S}>0$.

Proof of Lemma 3. Observe that $\partial^{2} \pi_{m R} / \partial \delta_{m 2}^{2}<0$; thus, $\pi_{m R}$ is concave in $\delta_{m 2}$. Therefore, the optimal advance selling discount $\delta_{m 2}^{*}$ is given by

$$
\delta_{m 2}^{*}=\frac{\left(1-\delta_{c}\right) Q^{2}+\delta_{c} p Q+p(Q-\alpha)+r \alpha}{2 p Q} .
$$

Substituting $\delta_{m 2}^{*}$ into equation (27) shows that $\pi_{m S}$ is decreasing in $D_{m}$. By incorporating the supplier's financial constraint in equation (27), we can verify that $\partial \pi_{m S} / \partial \delta_{m 1}>0$ and $\partial^{2} \pi_{m S} / \partial \delta_{m 1}^{2}<0$, which implies that the supplier's profit $\pi_{m S}$ is concave in $\delta_{m 1}$. Moreover, if $\left(1-\delta_{c}\right)(Q-p) Q+$ $(p-2 r) \alpha>0$, then $\delta_{m 2}^{*}<\delta_{2}^{*}$, which implies that the supplier can increase the supply chain's total profit by setting a minimum order quantity. Also, it is easy to determine that $\partial \delta_{m 2}^{*} / \partial \delta_{c}<0, \partial \delta_{m 2}^{*} / \partial \alpha<0, \partial \delta_{m 2}^{*} / \partial Q>0, \partial \delta_{m 2}^{*} / \partial p<0$, and $\partial \delta_{m 2}^{*} / \partial r>0$.

Similarly, observe that $\partial^{2} \pi_{b R} / \partial \delta_{b 2}^{2}<0$; thus, $\pi_{b R}$ is concave in $\delta_{b 2}$. Therefore, the optimal advance selling discount $\delta_{b 2}^{*}$ is given by

$$
\delta_{b 2}^{*}=\frac{\left(1-\delta_{c}\right) Q^{2}+\delta_{c} p Q+p(Q-\alpha)+b \alpha}{2 p Q} .
$$

On substituting $\delta_{b 2}^{*}$ into equation (30), we see that $\pi_{b S}$ is decreasing in $D_{b}$. By incorporating the supplier's financial constraint in equation (30), we can verify that $\partial \pi_{b S} / \partial \delta_{b 1}>0$ and $\partial^{2} \pi_{b S} / \partial \delta_{b 1}^{2}<0$, which implies that the supplier's profit $\pi_{b S}$ is concave in $\delta_{b 1}$. If $\left(1-\delta_{c}\right)(Q-p) Q+(p-2 b) \alpha>0$, then $\delta_{b 2}^{*}<\delta_{2}^{*}$, which implies that the supplier can increase the supply chain's total profit by setting a minimum order quantity and buying back the surplus products. Also, it is 
easy to determine that $\partial \delta_{b 2}^{*} / \partial \delta_{c}<0, \partial \delta_{b 2}^{*} / \partial \alpha<0, \partial \delta_{b 2}^{*} / \partial Q>0$, $\partial \delta_{b 2}^{*} / \partial p<0$, and $\partial \delta_{b 2}^{*} / \partial b>0$.

\section{Data Availability}

The data used to support the findings of this study are included within the article.

\section{Conflicts of Interest}

The authors declare that they have no conflicts of interest.

\section{Acknowledgments}

This work was supported by the National Key R\&D Program of China (Grant no. 018YFB1601401) and the National Natural Science Foundation of China (Grant nos. 71631006 and 71921001).

\section{References}

[1] W. Peng, Z. Tian, and Y. Wang, "Price guarantee for advance selling in the presence of preorder-dependent social learning," International Journal of Production Economics, vol. 219, pp. 115-122, 2020.

[2] M. Hu, J. Milner, and J. Wu, "Liking and following and the newsvendor: operations and marketing policies under social influence," Management Science, vol. 62, no. 3, pp. 867-879, 2015.

[3] P. Shao and P. Hu, "Product diffusion using advance selling strategies: an online social network perspective," Journal of Artificial Societies and Social Simulation, vol. 20, no. 2, 2017.

[4] T. I. Tunca and W. Zhu, "Buyer intermediation in supplier finance," Management Science, vol. 64, no. 12, pp. 5631-5650, 2017.

[5] Y. Aviv and A. Pazgal, "Optimal pricing of seasonal products in the presence of forward-looking consumers," Manufacturing \& Service Operations Management, vol. 10, no. 3, pp. 339-359, 2008.

[6] G. P. Cachon and R. Swinney, "Purchasing, pricing, and quick response in the presence of strategic consumers," Management Science, vol. 55, no. 3, pp. 497-511, 2009.

[7] M. M. Wei and F. Zhang, "Advance selling to strategic consumers: preorder contingent production strategy with advance selling target," Production and Operations Management, vol. 27, no. 7, pp. 1221-1235, 2018.

[8] X. Su and F. Zhang, "Strategic customer behavior, commitment, and supply chain performance," Management Science, vol. 54, no. 10, pp. 1759-1773, 2008.

[9] G. P. Cachon and M. A. Lariviere, "Supply chain coordination with revenue-sharing contracts: strengths and limitations," Management Science, vol. 51, no. 1, pp. 30-44, 2005.

[10] H. P. Young, "Innovation diffusion in heterogeneous populations: contagion, social influence, and social learning," American Economic Review, vol. 99, no. 5, pp. 1899-1924, 2009.

[11] F. M. Bass, "A new product growth for model consumer durables," Management Science, vol. 15, no. 5, pp. 215-227, 1969.

[12] V. Mahajan and E. Muller, "When is it worthwhile targeting the majority instead of the innovators in a new product launch?" Journal of Marketing Research, vol. 35, no. 4, pp. 488-495, 1998.
[13] C. Van den Bulte and Y. V. Joshi, "New product diffusion with influentials and imitators," Marketing Science, vol. 26, no. 3, pp. 400-421, 2007.

[14] T. H. Ho, S. Li, S. E. Park, and S. Z. J. Max, "Customer influence value and purchase acceleration in new product diffusion," Marketing Science, vol. 31, no. 2, pp. 236-256, 2012.

[15] Y. Papanastasiou and N. Savva, "Dynamic pricing in the presence of social learning and strategic consumers," Management Science, vol. 63, no. 4, pp. 919-939, 2016.

[16] A. Susarla, J. H. Oh, and Y. Tan, "Social networks and the diffusion of user-generated content: evidence from YouTube," Information Systems Research, vol. 23, no. 1, pp. 23-41, 2012.

[17] C. F. Manski, "Identification of endogenous social effects: the reflection problem," The Review of Economic Studies, vol. 60, no. 3, pp. 531-542, 1993.

[18] B. Sun, J. Xie, and H. H. Cao, "Product strategy for innovators in markets with network effects," Marketing Science, vol. 23, no. 2, pp. 243-254, 2004.

[19] N. N. Chau and R. Desiraju, "Product introduction strategies under sequential innovation for durable goods with network effects," Production and Operations Management, vol. 26, no. 2, pp. 320-340, 2017.

[20] I. V. Kozlenkova, E. Fang, B. Xiao, and R. W. Palmatier, "Online relationship marketing," Journal of the Academy of Marketing Science, vol. 47, no. 3, pp. 369-393, 2019.

[21] L. Steinhoff, D. Arli, S. Weaven, and I. V. Kozlenkova, "Online relationship marketing," Journal of the Academy of Marketing Science, vol. 47, no. 3, pp. 369-393, 2019.

[22] C. S. Tang, K. Rajaram, A. Alptekinoğlu, and J. Ou, "The benefits of advance booking discount programs: model and analysis," Management Science, vol. 50, no. 4, pp. 465-478, 2004.

[23] S. S. Ma, W. Xing, X. H. Liu, and L. Y. Wang, "Advance booking discount for risk-averse firm in the presence of spot market," Emerging Markets Finance and Trade, 2019.

[24] M. Ellman and S. Hurkens, "Optimal crowdfunding design," Journal of Economic Theory, vol. 184, 2019.

[25] F. Xu and F. Zhang, "Crowdfunding under social learning and network externalities,” SSRN Electronic Journal, 2018.

[26] M. Reindorp, F. Tanrisever, and A. Lange, "Purchase order financing: credit, commitment, and supply chain consequences," Operations Research, vol. 66, no. 5, pp. 1287-1303, 2018.

[27] S. Deng, C. Gu, G. Cai, and Y. Li, "Financing multiple heterogeneous suppliers in assembly systems: buyer finance vs. bank finance," Manufacturing \& Service Operations Management, vol. 20, no. 1, pp. 53-69, 2018.

[28] Z. Zhao, M. L. Chen, and W. K. Zhang, "Social community, personal involvement and psychological processes: a study of impulse buying in the online shopping carnival," Journal of Electronic Commerce Research, vol. 20, no. 4, pp. 255-272, 2019.

[29] T. Togawa, H. Ishii, N. Onzo, and R. Roy, "Effects of consumers' construal levels on post-impulse purchase emotions," Marketing Intelligence \& Planning, 2019.

[30] M. L. Katz and C. Shapiro, "Network externalities, competition, and compatibility," American Economic Review, vol. 75, no. 3, pp. 424-440, 1985.

[31] R. Sankaranarayanan, "Innovation and the durable goods monopolist: the optimality of frequent new-version releases," Marketing Science, vol. 26, no. 6, pp. 774-791, 2007.

[32] G. Ellison and D. Fudenberg, "The neo-luddite's lament: excessive upgrades in the software industry," The RAND Journal of Economics, vol. 31, no. 2, pp. 253-272, 2000. 
[33] G. Raz, C. T. Druehl, and V. Blass, "Design for the environment: life-cycle approach using a newsvendor model," Production and Operations Management, vol. 22, no. 4, pp. 940-957, 2013.

[34] T. Yalcin, E. Ofek, O. Koenigsberg, and E. Biyalogorsky, "Complementary goods: creating, capturing, and competing for value," Marketing Science, vol. 32, no. 4, pp. 554-569, 2013.

[35] J. Wang and H. Shin, "The impact of contracts and competition on upstream innovation in a supply chain," Production and Operations Management, vol. 24, no. 1, pp. 134-146, 2015. 